\title{
m-MMBP Characterization of the Departure Process of an m-MMBP/Geo/1/K Queue
}

Dooyeong Park

Harry G. Perros

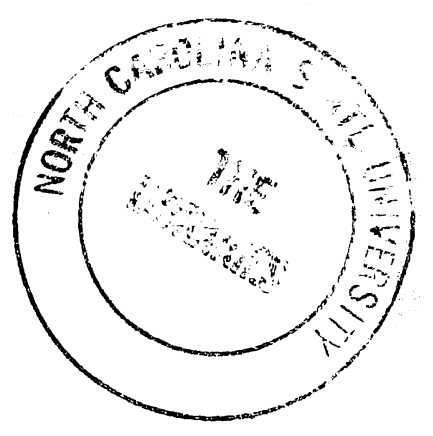

(Center for Communications and Signal Processing)

Department of Computer Science (North Carolina State University)

TK5101

AI

$T 72$

93/1

1993 


\title{
$m$-MMBP Characterization of the Departure Process of an $m$-MMBP/Geo/1/K Queue
}

\author{
Dooyeong Park \\ Department of Electrical and Computer Engineering, and \\ Center for Communications and Signal Processing \\ North Carolina State University \\ Raleigh, NC 27695 \\ Harry G. Perros \\ Department of Computer Science, and \\ Center for Communications and Signal Processing \\ North Carolina State University \\ Raleigh, NC 27695
}

Abstract. We approximate the departure process of an m-state $\mathrm{MMBP} / \mathrm{Geo} / 1 / \mathrm{K}$ queue for $m>2$ by an $m$-state MMBP in order to capture the burstiness and correlation of the departure process. A tractable approximation model is proposed and its accuracy is examined through extensive validation tests. Further validation is carried out by employing this model in a simple decomposition algorithm which is used to analyze a tandem conflguration of finite capacity queues with customer loss. Comparisons against simulation showed that the decomposition algorithm has a satisfactory accuracy. 


\section{Introduction}

In recent years there has been a lot of interest in the development of high-speed communication networks. The most promising design for high-speed networks is the Asynchronous Transfer Mode (ATM). The need for performance evaluation of ATM networks has given rise to a widespread interest for the analysis of discrete-time queueing systems. Discrete-time single server queues with or without finite capacity have been extensively analyzed. For a review of relevant results see Pujolle and Perros [1]. However, little has been done for the analysis of networks of discrete-time finite capacity queues. A network of discrete-time finite capacity queues can be used to model the queueing within an ATM switch, or the queueing within a network of ATM switches. The external arrival process to the network is assumed to be bursty. Markov Modulated Poisson Processes (MMPP) [2], [3], and Markov Modulated Bernoulli Processes (MMBP) are used to model a bursty arrival stream since they capture the randomly varying arrival rate. The MMPP and MMBP capture the notion of burstiness and the correlation of successive interarrival times. The Interrupted Bernoulli Process (IBP) is a special case of the MMBP.

In general, discrete-time queueing networks as they arise in ATM do not lend themselves to an exact analysis. They can be analyzed, however, approximately using the notion of decomposition. That is, the network is decomposed into individual queues, and each queue is then analyzed separately. One of the problems that arise in a decomposition is the characterization of the departure process from a queue. In continuous-time queueing networks, typically, such as the process is characterized approximately by a phased-type distribution, or by a general distribution defined by the mean and squared coefficient of variation.

In this paper, the departure process from a discrete-time queue is characterized approximately by an $m$-state MMBP (hereafter referred to as $m$-MMBP). In particular, we consider an $m$-MMBP/Geo/ $1 / \mathrm{K}$ queue, where the arrival process is an $m$-MMBP with $m>2$, and the service time is assumed to be geometric. The choice of the geometric distribution was motivated by ATM networks. In general, a service time represents a transmission time. In an 
ATM network, the size of a packet (commonly known as cell) is constant, and therefore the transmission time is constant as well. However, in some ATM switch architectures a cell may be re-transmitted several times due to back pressure or possible collisions with other cells. In this case, the total transmission time is typically modeled by a geometric distribution.

A tractable approximation model is proposed to characterize the departure process from this queue by an $m$-MMBP with $m>2$. The accuracy of the model has been examined through extensive validation tests. The problem of fitting a discrete-time distribution to the departure process of a discrete-time queue is relatively unexplored. Park and Perros [4] approximated the departure process of an IBP/Geo/1/K queue by an IBP. Also, Park, Perros and Yamashita [5] approximated the departure process of a 2-MMBP/Geo/1/K queue by a 2-MMBP. Stavrakakis [6] developed models for characterizing the packet traffic modulated by merging and/or splitting operations by a discrete-time Markovian process. Meier [7] developed an iterative algorithm for fitting an MMPP to observational data based on maximum likelihood estimation. The interdeparture distribution of a discrete-time GI/G/1 queue has been obtained by Tran-Gia [8] using the Fast Fourier Transform. He also derived the idle period distribution from the equilibrium distribution of the virtual unfinished work. Ohba, Murata and Miyahara [9] analyzed a discrete-time single-server infinite capacity queue with the following three arrival streams: 1) arrivals with a general interarrival time distribution (referred to as GI-stream), 2) Bernoulli arrivals in batches, and 3) IBP. They obtained the departure process for the GI-stream.

This paper is organized as follows. In section 2 , we give a brief description of the $m$ MMBP. The generating function of the interdeparture time of an $m-\mathrm{MMBP} / \mathrm{Geo} / 1 / \mathrm{K}$ queue and the correlation coefficients of the departure process are obtained in section 3 . In section 4 , we present a fitting model for characterizing the departure process as an $m$-MMBP and we examine its accuracy. In section 5 , we analyze a tandem configuration of finite capacity queues with cell loss using the fitting model obtained in section 4 . The approximate results are compared against simulation in section 5. Finally, conclusions are given in section 6 . 


\section{The $m$-state Markov Modulated Bernoulli Process}

\subsection{The Generating Function of the Interarrival Time Distribu- tion}

An $m$-MMBP is a Bernoulli process whose rate varies according to an $m$-state Markov chain. It is characterized by the transition probability matrix $\mathrm{P}$ of the Markov process and $\Lambda, m \times m$ diagonal matrix with elements $\alpha_{1}, \cdots, \alpha_{m}$ given by

$$
\mathbf{P}=\left[\begin{array}{ccc}
p_{11} & & p_{1 m} \\
& \ddots & \\
p_{m 1} & & p_{m m}
\end{array}\right] \quad \text { and } \quad \boldsymbol{\Lambda}=\left[\begin{array}{ccc}
\alpha_{1} & & 0 \\
& \ddots & \\
0 & & \alpha_{m}
\end{array}\right]
$$

where $p_{i j}, 1 \leq i, j \leq m$, is the transition probability that the MMBP changes from state $i$ to state $j$ and $\sum_{j=1}^{m} p_{i j}=1$ for $1 \leq i \leq m$. We say that the MMBP is in state $i, 1 \leq i \leq m$, when the Markov process is in state $i$. When the MMBP is in state $i, 1 \leq i \leq m$, arrivals occur with a probability $\alpha_{i}$.

Let $T$ be the interarrival time between two successive arrivals. Also, let

$$
\overrightarrow{\mathbf{p}}_{a}=\frac{\pi \Lambda}{\pi \vec{\lambda}}=\left[p_{a 1}, p_{a 2}, \cdots, p_{a m}\right], \quad \vec{\lambda}=\left[\alpha_{1}, \cdots, \alpha_{m}\right]^{T}, \quad \text { and } \quad \mathrm{M}=\mathrm{P}(\mathrm{I}-\boldsymbol{\Lambda})
$$

where $p_{a i}$ can be interpreted as the probability that given an arrival, it occurs from state $i, 1 \leq i \leq m$ and $\pi$ is the steady-state probability vector satisfying $\pi=\pi \mathrm{P}$. The generating function of the interarrival time $T(z)$ can be obtained as follows (see [5]):

$$
T(z)=\overrightarrow{\mathbf{p}}_{a} \overrightarrow{\mathrm{T}}(z)
$$

where $\overrightarrow{\mathrm{T}}(z)=z(\mathrm{I}-z \mathrm{M})^{-1} \mathrm{P} \vec{\lambda}$.

By differentiating equation (1), we can obtain the moments of the time between two successive arrivals. The average arrival rate $\rho$, and the squared coefficient of variation of the interarrival time $C^{2}$ are as follows:

$$
\rho=\frac{1}{T^{(1)}(1)}=\pi \vec{\lambda}
$$




$$
C^{2}=T^{(2)}(1) \rho^{2}+\rho-1
$$

where

$$
T^{(n)}(1)=\left.\frac{d^{n} T(z)}{d z^{n}}\right|_{z=1}=n ! \overrightarrow{\mathrm{p}}_{a}(\mathrm{I}-\mathrm{M})^{-(n+1)} \mathrm{M}^{n-1} \mathrm{P} \vec{\lambda}
$$

Note that

$$
\overrightarrow{\mathbf{T}}^{(n)}(z)=\frac{d^{n} \overrightarrow{\mathbf{T}}(z)}{d z^{n}}=n !\left[(\mathbf{I}-z \mathbf{M})^{-1} \mathrm{M}\right]^{n-1}(\mathrm{I}-z \mathrm{M})^{-1}\left[\mathbf{I}+z \mathrm{M}(\mathrm{I}-z \mathrm{M})^{-1}\right] \mathbf{P} \vec{\lambda}
$$

We have the closed-form expressions of $\rho$ and $C^{2}$ of the 2-MMBP as follows:

$$
\begin{aligned}
\rho & =\frac{p_{21} \alpha_{1}+p_{12} \alpha_{2}}{p_{12}+p_{21}} \\
C^{2} & =\frac{2 \rho\left[\left(p_{12}+p_{21}\right)^{2}+\left(p_{12} \alpha_{1}+p_{21} \alpha_{2}\right)\left(p_{11}+p_{22}-1\right)\right]}{\left(p_{12}+p_{21}\right)\left[p_{21} \alpha_{1}+p_{12} \alpha_{2}+\alpha_{1} \alpha_{2}\left(p_{11}+p_{22}-1\right)\right]}-\rho-1 .
\end{aligned}
$$

From equations ( 1 ) and (2), we can obtain the interarrival time distribution of an $m$-MMBP as follows:

$$
P(T=n)=\overrightarrow{\mathbf{p}}_{\mathbf{a}} \mathrm{M}^{n-1} \mathrm{P} \vec{\lambda}
$$

where $P(T=n)$ is the probability that the interarrival time is equal to $n$ slots.

Let $t_{n}$ be the time interval between the $(n-1)$ st and the $n$th arrival. Then, we have

$$
E\left\{t_{n} t_{n+k}\right\}=\overrightarrow{\mathbf{p}}_{a}(\mathrm{I}-\mathrm{M})^{-2} \mathrm{P} \Lambda \mathrm{T}^{k-1}(\mathrm{I}-\mathrm{M})^{-2} \mathrm{P} \vec{\lambda}
$$

The correlation coefficient of the interarrival time of an $m$-MMBP for lag $k, \psi(k)$, is given by

$$
\psi(k)=\frac{E\left\{t_{n} t_{n+k}\right\}-E^{2}\left\{t_{n}\right\}}{\operatorname{Var}\left\{t_{n}\right\}}
$$

In particular, $\psi(1)$ for the 2 -MMBP is given by

$$
\psi(1)=\frac{\alpha_{1} \alpha_{2}\left(\alpha_{1}-\alpha_{2}\right)^{2} p_{12} p_{21}\left(p_{11}+p_{22}-1\right)^{2}}{C^{2}\left(p_{12}+p_{21}\right)^{2}\left[p_{21} \alpha_{1}+p_{12} \alpha_{2}+\alpha_{1} \alpha_{2}\left(p_{11}+p_{22}-1\right)\right]^{2}} .
$$


Let $X_{n}$ be the random variable representing the number of arrivals at $n$th slot, where $X_{n}=0,1$. Then, we have (see $\left.[10]\right)$

$$
\begin{aligned}
E\left\{X_{n}\right\} & =\pi \vec{\lambda}=\rho, \\
E\left\{X_{n} X_{n+k}\right\} & =\pi \Lambda \mathrm{P}^{k} \vec{\lambda} \\
\operatorname{Var}\left\{X_{n}\right\} & =E\left\{X_{n}\right\}-E^{2}\left\{X_{n}\right\} .
\end{aligned}
$$

Of interest is the autocorrelation coefficient of the number of arrivals of an $m$-MMBP for lag $k, \phi(k)$, given by

$$
\phi(k)=\frac{E\left\{X_{n} X_{n+k}\right\}-E^{2}\left\{X_{n}\right\}}{\operatorname{Var}\left\{X_{n}\right\}} .
$$

For a 2 -MMBP

$$
\phi(i)=\frac{p_{12} p_{21}\left(\alpha_{1}-\alpha_{2}\right)^{2}\left(p_{11}+p_{22}-1\right)^{i}}{\left(p_{21} \alpha_{1}+p_{12} \alpha_{2}\right)\left[p_{21}\left(1-\alpha_{1}\right)+p_{12}\left(1-\alpha_{2}\right)\right]} .
$$

\section{The Departure Process of an $m-\mathrm{MMBP} / \mathrm{Geo} / 1 / \mathrm{K}$ Queue}

We consider an $m$-MMBP/Geo/1/K queue, where the service time is defined over a slotted time axis. A service always starts at the beginning of a service slot, and the service time is assumed to be a geometrically distributed number of service slots with parameter $\sigma$. Service completion is assumed to take place just before the end of a service slot. The arrival process is also defined over a slotted time axis with the same slot size, and it is assumed to be an $m$-MMBP with $m>2$. The parameters of the arrival process are: $p_{i j}^{A}$ and $\alpha_{i}^{A}$, where $p_{i j}^{A}$ is the $(i, j)$ th element of the transition probability matrix $\mathrm{P}$ and $\alpha_{i}^{A}$ is the $(i, i)$ th element of the diagonal matrix $\Lambda$. The boundaries of the slots of the arrival process are assumed to be in-between the boundaries of the service slots. An arriving customer to an empty queue cannot start its service until the beginning of the next service slot, even though the server is free at the instant of its arrival. We examine this queue at the boundary of each service slot. We define the state of the queue by the variables $(s, n)$. Variable $s$ represents the state 
of the arrival process at the end of a slot and it takes the values: $i, 1 \leq i \leq m$, if the arrival process is in the state $i$. Variable $n$ indicates the number of cells in the system at the end of a slot. We have $n=0,1, . ., \mathrm{K}$, where $\mathrm{K}$ is the capacity of the system including the cell in service. Let $\mathbf{P}_{d}$ be the transition probability matrix of the queue. We can see that $\mathbf{P}_{d}=\mathbf{P}_{w d}+\mathbf{P}_{\text {wod }}$, where $\mathbf{P}_{w d}, \mathbf{P}_{w o d}$, is a matrix that contains transitions with a departure respectively without a departure. We compute the generating function of the probability distribution of the interdeparture time, and then we obtain the autocorrelation of the interdeparture time and the autocorrelation of the number of departures per slot.

\subsection{The Generating Function of the Interdeparture Time Distri- bution}

Let $I$ be a random variable representing the time elapsing from the moment a departure occurs leaving an empty system behind to the end of a slot during which an arrival occurs. In order to simplify the presentation below, we set $I=0$ for the special case where a departing customer leaves a non-empty system behind. Also, let $S$ and $D$ be random variables representing the service time and the interdeparture time, respectively. $I$ can be expressed as follows:

$$
I=\left\{\begin{array}{cc}
0 & 1-\sum_{i=1}^{m} P^{+}(i, 0) \\
I_{1} & P^{+}(1,0) \\
\vdots & \vdots \\
I_{m} & P^{+}(m, 0)
\end{array}\right.
$$

where $I_{i}, 1 \leq i \leq m$, is a random variable indicating the time elapsing from the moment the system is in state $(i, 0)$ to the end of a slot during which an arrival occurs. $P^{+}(s, n)$ is the probability that immediately after a departure the system is in state $(s, n) . I_{i}, 1 \leq i \leq m$, 
and $P^{+}(s, n)$ are as follows:

$$
\begin{aligned}
& I_{\mathbf{i}}=\left\{\begin{array}{cc}
1 & \sum_{j=1}^{m} p_{i j}^{A} \alpha_{j}^{A} \\
1+I_{1} & p_{i 1}^{A}\left(1-\alpha_{1}^{A}\right) \\
\vdots & \vdots \\
1+I_{m} & p_{i m}^{A}\left(1-\alpha_{m}^{A}\right)
\end{array}\right. \\
& \overrightarrow{\mathbf{P}}^{+}=\left[P^{+}(1,0), \cdots, P^{+}(m, 0), P^{+}(1,1), P^{+}(2,1), \cdots, P^{+}(m, K)\right]=\frac{\mathbf{x} \mathbf{P}_{w d}}{\mathbf{x} \vec{\lambda}_{d}}
\end{aligned}
$$

where $\vec{\lambda}_{d}=[0, \cdots, 0,1-\sigma, \cdots, 1-\sigma]^{T}$ and $\mathbf{x}$ is the steady state probability vector satisfying $\mathbf{x P}_{d}=\mathbf{x}$. Let

$$
\overrightarrow{\mathrm{I}}_{p}(z)=\left[I_{1}(z), \cdots, I_{m}(z)\right]^{T}
$$

where $I_{i}(z)$ is the z-transform of $I_{i}, 1 \leq i \leq m$. Note that $\overrightarrow{\mathrm{I}}_{p}(z)=\overrightarrow{\mathrm{T}}(z)$.

We define $D(z)$ and $S(z)$ as the generating function of $D$ and $S$, respectively. Then, we have

$$
D(z)=I(z) S(z)=\overrightarrow{\mathrm{P}}^{+}\left[\begin{array}{c}
\overrightarrow{\mathrm{T}}(z) \\
\overrightarrow{\mathrm{e}}
\end{array}\right] S(z)
$$

where $I(z)$ is the generating function of the period $I, S(z)=\frac{(1-\sigma) z}{1-\sigma z}$, and $\overrightarrow{\mathbf{e}}=[1, \cdots, 1]^{T}$. Let

$$
D^{(n)}(1)=\left.\frac{d^{n} D(z)}{d z^{n}}\right|_{z=1} \quad \text { and } \quad \overrightarrow{\mathrm{I}}(z)=\left[\begin{array}{c}
\overrightarrow{\mathrm{T}}(z) \\
\overrightarrow{\mathbf{e}}
\end{array}\right]
$$

Then, we have

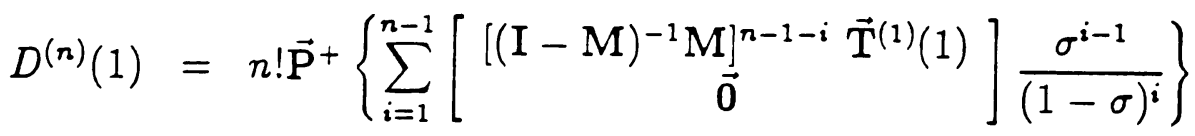

$$
\begin{aligned}
& +n !\left\{\overrightarrow{\mathrm{P}}^{+}\left[\begin{array}{cc}
{\left[(\mathrm{I}-\mathrm{M})^{-1} \mathrm{M}\right]^{n-1}} & \overrightarrow{\mathrm{T}}^{(1)}(1) \\
\overrightarrow{\mathbf{0}} &
\end{array}\right]+\frac{\sigma^{n-1}}{(1-\sigma)^{n}}\right\} .
\end{aligned}
$$

Using equation (6), we can obtain the moments of the time between successive departures, the squared coefficient of variation of the interdeparture time $C_{d}^{2}$, and the throughput $\rho_{d}$. 
From the generating function, $D(z)$ we also can obtain the interdeparture time distribution recursively as follows:

$$
\begin{aligned}
& P(D=1)=(1-\sigma)\left[1-\sum_{i=1}^{m} P^{+}(i, 0)\right] \\
& P(D=n)=\overrightarrow{\mathrm{P}}^{+}\left[\begin{array}{c}
\mathrm{M}^{n-2} \mathbf{P} \vec{\lambda} \\
\overrightarrow{0}
\end{array}\right](1-\sigma)+\sigma P(D=n-1) \text { for } n \geq 2
\end{aligned}
$$

where $P(D=n)$ is the probability that the interdeparture time is equal to $n$ slots.

\subsection{Autocorrelation of the Departure Process}

In this section, we obtain the autocorrelation of the interdeparture time, and the autocorrelation of the number of departures per slot (see [5]). Let $t_{n}$ be the time interval between the $(n-1)$ st and the $n$th departure. Also, let $t_{i j}^{n}, 1 \leq i, j \leq N$ where $N=m(K+1)$, be the time interval to the moment that the state of the queue is $j$ and the $n$th departure occurs given that the queue is in state $i$, and $t_{i}^{n}, 1 \leq i \leq N$, be the time interval to the $n$th departure given that the queue is in state $i$. Define

$$
\mathrm{D}(z)=\left[\begin{array}{ccc}
D_{11}(z) & & D_{1 N}(z) \\
& \ddots & \\
D_{N 1}(z) & & D_{N N}(z)
\end{array}\right] \quad \text { and } \quad \overrightarrow{\mathrm{D}}(z)=\left[\begin{array}{c}
D_{1}(z) \\
\vdots \\
D_{N}(z)
\end{array}\right]
$$

where $D_{i j}(z)$ and $D_{i}(z)$ are the z-transforms of $t_{i j}^{n}$ and $t_{i}^{n}$, respectively. From the definition of $D_{i j}(z)$ and $D_{i}(z)$, we have

$$
\mathrm{D}(z)=z\left(\mathrm{I}-z \mathrm{P}_{w o d}\right)^{-1} \mathrm{P}_{w d} \quad \text { and } \quad \overrightarrow{\mathrm{D}}(z)=\overrightarrow{\mathrm{I}}(z) S(z)
$$

Then, we have

$$
E\left\{z_{1}^{t_{n}} z_{2}^{t_{n+k}}\right\}=\overrightarrow{\mathrm{P}}^{+} \mathrm{D}\left(z_{1}\right) \mathrm{R}^{k-1} \overrightarrow{\mathrm{D}}\left(z_{2}\right)
$$

where

$$
\mathrm{R}=\left(\mathrm{I}-\mathrm{P}_{\text {wod }}\right)^{-1} \mathrm{P}_{w d}
$$


From equation (7), we have

$$
E\left\{t_{n} t_{n+k}\right\}=\overrightarrow{\mathbf{P}}^{+}\left[\mathbf{I}-\mathbf{P}_{w o d}\right]^{-2} \mathbf{P}_{w d} \mathbf{R}^{k-1}\left[\overrightarrow{\mathbf{I}}^{(1)}(1)+\frac{1}{1-\sigma} \overrightarrow{\mathbf{e}}\right]
$$

where

$$
\overrightarrow{\mathrm{I}}^{(1)}(1)^{T}=\left.\frac{d \overrightarrow{\mathrm{I}}(z)}{d z}\right|_{z=1} .
$$

The autocorrelation coefficient of the interdeparture times of an $m$-MMBP/Geo/1/K queue for lag $k, \psi_{d}(k)$, can now be obtained using expression (3).

Let $X_{n}$ be the random variable representing the number of departures in the $n$th slot, where $X_{n}=0,1$. We have

$$
E\left\{X_{n}\right\}=E\left\{X_{n}^{2}\right\}=\rho_{d} \quad \text { and } \quad E\left\{X_{n} X_{n+k}\right\}=\mathbf{x P}_{w d} \mathrm{P}_{d}^{k-1} \vec{\lambda}_{d}
$$

The autocorrelation coefficient of the number of departures of the queue for lag $k, \phi_{d}(k)$ can now be obtained from (4).

\section{Characterization of the Departure Process}

In this section, we obtain an approximation model for characterizing the departure process by an $m$-MMBP for $m>2$. This model captures the correlation and burstiness of the departure process of the queue. The fitted $m$-MMBP is characterized by the transition probability matrix $P_{\text {est }}$ of the Markov process and $\Lambda_{e s t}$ given by

$$
\mathbf{P}_{\text {est }}=\left[\begin{array}{ccc}
p_{11}^{\text {est }} & & p_{1 m}^{\text {est }} \\
& \ddots & \\
p_{m 1}^{\text {est }} & & p_{m m}^{\text {est }}
\end{array}\right] \text { and } \Lambda_{\text {est }}=\left[\begin{array}{ccc}
\alpha_{1}^{\text {est }} & & 0 \\
& \ddots & \\
0 & & \alpha_{m}^{\text {est }}
\end{array}\right]
$$

where $p_{i j}^{\text {est }}, 1 \leq i, j \leq m$, is the transition probability that the fitted MMBP changes from state $i$ to state $j, \sum_{j=1}^{m} p_{i j}^{\text {est }}=1$ for $1 \leq i \leq m$, and $\alpha_{i}^{\text {est }}, 1 \leq i \leq m$, is the probability that a slot contains a cell during the the the that the MMB is in state $i$. 
We note that an $m$-MMBP is characterized by $m^{2}$ parameters. For $m=2$, we can obtain the parameters, $p_{i j}^{\text {ept }}, 1 \leq i, j \leq 2$ and $\alpha_{i}^{\text {est }}, i=1,2$, by matching $\rho_{d}, C_{d}^{2}$, and the autocorrelation coefficients $\phi_{d}(1)$ and $\psi_{d}(1)$ of the departure process. The four parameters, $p_{11}^{\text {est }}, p_{22}^{\text {est }}, \alpha_{1}^{\text {est }}$, and $\alpha_{2}^{\text {est }}$ can be obtained from the following four equations (see [5]):

$$
\begin{aligned}
& \left\{4 C_{d}^{2}\left(1-\rho_{d}\right) \phi_{d}(1) \psi_{d}(1)+\left(C_{d}^{2}+\rho_{d}-1\right)\left[\left(C_{d}^{2}+\rho_{d}-1\right)-2\left(1-\rho_{d}\right) \phi_{d}(1)\right]\right\}\left(\alpha_{1}^{\text {est }}\right)^{2}- \\
& \left\{4 C_{d}^{2}\left(1-\rho_{d}^{2}\right) \phi_{d}(1) \psi_{d}(1)+\left(C_{d}^{2}+\rho_{d}-1\right)^{2} \rho_{d}+\left[\left(C_{d}^{2}-1\right)^{2}-\rho_{d}^{2}\right]\left(1-\rho_{d}\right) \phi_{d}(1)\right\} \alpha_{1}^{\text {est }}+ \\
& 4 C_{d}^{2}\left(1-\rho_{d}\right) \rho_{d} \phi_{d}(1) \psi_{d}(1)=0 \\
& \alpha_{2}^{\text {est }}=\frac{\rho_{d}\left(C_{d}^{2}+\rho_{d}-1\right)\left[\left(1-\rho_{d}\right) \phi_{d}(1)-\alpha_{1}^{\text {est }}+\rho_{d}\right]+2\left(\alpha_{1}^{\text {est }}-\rho_{d}\right) \rho_{d}\left(1-\rho_{d}\right) \phi_{d}(1)}{\left(1-\rho_{d}\right) \phi_{d}(1)\left[\left(C_{d}^{2}+\rho_{d}+1\right) \alpha_{1}^{\text {est }}-2 \rho_{d}\right]-\left(\alpha_{1}^{\text {est }}-\rho_{d}\right)\left(C_{d}^{2}+\rho_{d}-1\right)} \\
& p_{11}^{\text {est }}=1-\frac{\left(\alpha_{1}^{\text {est }}-\rho_{d}\right)\left(\rho_{d}-\alpha_{2}^{\text {est }}\right)-\rho_{d}\left(1-\rho_{d}\right) \phi_{d}(1)}{\left(\alpha_{1}^{\text {est }}-\alpha_{2}^{\text {est }}\right)\left(\rho_{d}-\alpha_{2}^{\text {est }}\right)} \\
& p_{22}^{\text {est }}=1-\frac{\left(\alpha_{1}^{\text {est }}-\rho_{d}\right)\left(\rho_{d}-\alpha_{2}^{\text {est }}\right)-\rho_{d}\left(1-\rho_{d}\right) \phi_{d}(1)}{\left(\alpha_{1}^{\text {est }}-\alpha_{2}^{\text {est }}\right)\left(\alpha_{1}^{\text {est }}-\rho_{d}\right)} .
\end{aligned}
$$

In this paper, our focus is on the case where $m>2$. It is practically impossible to obtain the parameters of an $m$-MMBP, $m>2$ using the method of moments, particularly when $m$ is large. Other fitting techniques, such as minimum distance estimation and least squared estimation, can be used, but they are time consuming. In this section, we present a simple and accurate method for fitting an $m$-MMBP to the departure process of an $m$ $\mathrm{MMBP} / \mathrm{Geo} / 1 / \mathrm{K}$ queue. We note that we do not address the problem of how many stages the fitted MMBP should consist of. We simply assume that it has as many stages as the MMBP describing the arrival process to the queue.

The departure process of a queue is governed by the state of the queue. Therefore, we can obtain valuable information regarding the departure process from the states of the queue. The parameters $p_{i j}^{\text {eat }}, 1 \leq i, j \leq m$, can be obtained from the state classification [4], [5], [11]. Unlike the case of the IBP, however, the state classification for the MMBP is not a simple task. It is difficult to determine which states of the queue belong to state $i, 1 \leq i \leq m$, of the fitted $m$-MMBP. Idealy, the grouping of the states should be done so that during the 
time that the queue is in any state of a group, the probability of departure during each slot is fairly uniform.

Intuitively speaking, during the busy period of the queue, the departure process is primarily affected by the service rate. That is, the probability that a customer will depart at each slot is $1-\sigma$. On the other hand, when the queue is empty, the departure process is likely to be affected by the state of the arrival process. To illustrate this point, let us assume that the queue is in state $(i, 0)$ and that $p_{i j}^{A}$ is large whereas $\alpha_{i}^{A}$ is small. Then, the queue is likely to stay in this state for some time, during which the departure process will be dominated by state $i$ of the arrival process.

We define $S_{i}, 1 \leq i \leq m$ to be the set of all states of the queue which belong to state $i$ of the $m$-MMBP departure process. We have the following grouping of the states:

$$
\begin{aligned}
S_{1}= & \left\{(1,0 \leq n \leq K),\left(2, k_{2}<n \leq K\right), \cdots,\left(m, k_{m}<n \leq K\right)\right\} \\
S_{2}= & \left\{\left(2,0 \leq n \leq k_{2}\right)\right\} \\
& \vdots \\
S_{m}= & \left\{\left(m, 0 \leq n \leq k_{m}\right)\right\}
\end{aligned}
$$

where $1 \leq k_{i} \leq K$ for $2 \leq i \leq m$. State $i$ of the departure process is associated with state $(i, 0)$ of the queue plus a few more states $(i, n), n \leq k_{i} \leq K$, where $k_{i}$ is to be determined. State 1 is associated with states $(i, n), n \geq k_{i}, i=2,3, \cdots, m$, which make up part of the busy period of the queue. Also, in order for the departure process to have same number of states as the arrival process, we include $(1, n), n=0,1, \cdots, K$, in $S_{1}$. We assume that state 1 of the arrival process is the state which has the highest probability of arrival per slot, i.e. $\alpha_{1}^{A}=\max _{i}\left(\alpha_{i}^{A}\right)$.

Using the steady-state probability, $P(s, n)$ and the transition probabilities from state $(s, n)$ to state $(\bar{s}, \bar{n}), t[(s, n) \rightarrow(\bar{s}, \bar{n})]$, the elements of the transition probability matrix, $p_{i j}^{\text {eat }}, 1 \leq$ $i, j \leq m$, can be calculated as follows:

$$
p_{i j}^{\text {est }}=\frac{\sum_{(s, n) \in S_{i}} P(s, n)\left[\sum_{(s, n) \in S_{j}} t[(s, n) \rightarrow(\bar{s}, \bar{n})]\right]}{\sum_{(s, n) \in S_{i}} P(s, n)} .
$$


Once $\mathbf{P}_{\text {est }}$ has been calculated, we can obtain $\Lambda_{\text {est }}$ by matching $\rho_{d}$ of the departure process. First, let $p_{a i}^{\text {est }}$ be the probability that given a departure, it occurs from state $i$ of the fitted $m$-MMBP. Also, define

$$
\overrightarrow{\mathbf{p}}_{a}^{\text {eat }}=\left[p_{a 1}^{\text {est }}, \cdots, p_{a m}^{e s t}\right]
$$

Then, we have

$$
\overrightarrow{\mathbf{p}}_{a}^{\text {est }}=\frac{\pi_{\text {est }} \Lambda_{\text {est }}}{\pi_{\text {est }} \vec{\lambda}_{\text {est }}}=\frac{1}{\rho_{\text {est }}}\left[\pi_{1}^{\text {est }} \alpha_{1}^{\text {est }}, \cdots, \pi_{m}^{\text {est }} \alpha_{m}^{\text {est }}\right]
$$

where $\vec{\lambda}_{\text {est }}=\left[\alpha_{1}^{\text {est }}, \cdots, \alpha_{m}^{\text {est }}\right]^{T}$ and $\pi_{\text {est }}$ is the stationary probability vector satisfying $\pi_{\text {est }} \mathrm{P}_{\text {est }}=$ $\pi_{\text {est }}$. Also, let $p_{d i}$ be the probability that given a departure, it occurs from $S_{i}$. Then, we have

$$
p_{d i}=\frac{1-\sigma}{\rho_{d}}\left[\sum_{\substack{(s, n) \in S_{i} \\ n \neq 0}} P(s, n)\right]
$$

By setting $\rho_{\text {est }}=\rho_{d}$ and $p_{a i}^{\text {est }}=p_{d i}$, we have

$$
\alpha_{i}^{\text {est }}=\frac{p_{d i} \rho_{d}}{\pi_{i}^{\text {est }}} \quad \text { for } \quad 1 \leq i \leq m
$$

This method always gives a feasible set of parameters which satisfy the basic conditions, $0<p_{i j}^{\text {est }}<1$ and $0<\alpha_{i}^{\text {est }} \leq 1$ for $1 \leq i, j \leq m$. In the fitted MMBP, a state transition can be caused by a departure. That is when a departure occurs, the state of the queue will change if no arrival has occurred. A state change may cause a change in the state of the departure process. Thus, a departure from the queue may cause the departure process to change state, which is not the case in an MMBP.

We now proceed to calculate the parameters, $k_{i}, i=2,3, \cdots, m$, which determine the classification of the states of the queue to the $m$ groups $S_{i}, i=1,2, \cdots, m$. We can determine $k_{i}, i=2,3, \cdots, m$, by first forming all possible groupings of the states of the queue, and then choosing the one which best matches one of the characteristics of the departure process, such as the interdeparture time distribution, or the correlation of the departure process. This 
approach, however, is very time-consuming, particularly when $m$ is large $(m \geq 6)$. Below, we present various empirical rules for determining $k_{i}, 2 \leq i \leq m$.

As it was mentioned above, the state classification was done based on the following two arguments: a) When the queue is not empty, the departure rate in a slot depends only on the parameter of the service time distribution $\sigma$. b) When the queue is empty, the departure rate in a slot depends on the state of the arrival process. For each $S_{i}, 2 \leq i \leq m$, we select all states $(i, n), n=0,1, \cdots, k_{i}$, so that to reduce the possibility of a state change in the departure process due to a departure. This is achieved by selecting only those states for which $P(i, n) \geq p$. Four different rules for selecting $p$ are proposed below.

Rule 1: $S_{i}=\left\{(i, n):(i, 1),(i, 2), \cdots,\left(i, k_{i}\right)\right.$ so that $P\left(i, k_{i}\right) \geq 1.0 \mathrm{E}-2$ and $\left.P\left(i, k_{i}+1\right)<1.0 \mathrm{E}-2\right\}$ for $2 \leq i \leq m$ $S_{1}=\{$ all remaining states $\}$

Rule 2: $S_{i}=\left\{S_{i}\right.$ per Rule 1$\} \cup\{(i, n) ; 1.0 \mathrm{E}-3 \leq P(i, k)<1.0 \mathrm{E}-2, n=\min (k)\}$ for $2 \leq i \leq m$ $S_{1}=\{$ all remaining states $\}$

Rule 3: $S_{i}=\left\{(i, n):(i, 1),(i, 2), \cdots,\left(i, k_{i}\right)\right.$ so that $P\left(i, k_{i}\right) \geq 1.0 \mathrm{E}-3$ and $\left.P\left(i, k_{i}+1\right)<1.0 \mathrm{E}-3\right\}$ for $2 \leq i \leq m$ $S_{1}=\{$ all remaining states $\}$

Rule 4: $S_{i}=\left\{S_{i}\right.$ per Rule 3 $\} \cup\{(i, n) ; 1.0 \mathrm{E}-4 \leq P(i, k)<1.0 \mathrm{E}-3, n=\min (k)\}$ for $2 \leq i \leq m$ $S_{1}=\{$ all remaining states $\}$

Extensive tests were carried out in order to establish the accuracy of the estimated MMBP under the above 4 different rules. In particular, we considered an $m$-MMBP/Geo/ $/ \mathrm{K}$ queue with $\mathrm{K}=8, \sigma=0.1$, and $m=4,6,8$. The parameters of the arrival process were varied so that the departure process corresponded to different values for $\rho_{d}, C_{d}^{2}, \psi_{d}(1)$, and $\phi_{d}(1) .24$ different test cases were thus created. The characteristics of the arrival process and the corresponding departure process for each test case are given in table 1.

One of the measure of accuracy employed was $\epsilon_{D}(n)$ given by

$$
\epsilon_{D}(n)=\sum_{i=1}^{n}\left|P(D=i)-P_{\text {est }}(D=i)\right|
$$

where $P_{\text {eat }}(D=i)$ is the estimated probability that the interdeparture time is equal to $i$ $\operatorname{slot}(s)$ and $n$ is the number of distribution points to be compared. $n$ was selected so that 
$\sum_{i=1}^{n} P(D=i) \simeq 1$. The value for $n$ for each test case also reported in table 1 . In table 6 , we summarize the best, worst, and average value for $\epsilon(n)$ when applying rule $i, i=1,2,3,4$, observed over all our validation tests. The detail validation test results are given in tables 25. In particular, tables $2-3$ are for the $4-\mathrm{MMBP}$, table 4 is for the $6-\mathrm{MMBP}$, and table 5 is for the 8-MMBP. For each case, we also give errors computed using the expressions

$$
\epsilon_{\psi}(n)=\sum_{i=1}^{n}\left|\psi_{d}(i)-\psi_{\text {est }}(i)\right| \quad \text { and } \quad \epsilon_{\phi}(n)=\sum_{i=1}^{n}\left|\phi_{d}(i)-\phi_{\text {est }}(i)\right|
$$

where $\psi_{\text {eat }}(i)$ is the estimated autocorrelation coefficient of the interdeparture time for lag $i$ and $\phi_{\text {est }}(i)$ is the estimated autocorrelation coefficient of the number of departures for lag $i$. We also give the values for $C_{\text {est }}^{2}, \psi_{\text {est }}(1)$, and $\phi_{\text {est }}(1)$. The results obtained are given separately for each rule $i, i=1,2,3,4$. In tables $2-3$, we also give results obtained using a search method which tests all possible groupings of the states of the queue and selects the one with the smallest $\epsilon_{D}(n)$ or $\epsilon_{\psi}(n)$. From Table 6 , we see that each of the 4 rules has the same accuracy. In general, rule 4 gives better results than the other three rules except for the case when the autocorrelation and the squared coefficient of variation of the interdeparture time is small. Also, all four rules give better results when the departure process is bursty and correlated. In general, we also see that for all four rules, the autocorrelation of the interdeparture time is overestimated and the squared coefficient of variation of the interdeparture time is underestimated when the autocorrelation of the interdeparture time is small and $C_{d}^{2}$ is large.

\section{Analysis of a Tandem Configuration with Cell Loss}

In this section, we further validate the fitting model described in the previous section by using it to analyze approximately a tandem configuration of discrete-time finite capacity queues. Let us consider an open queueing network consisting of $N$ nodes linked in tandem as shown in figure 1. The nodes are numbered from 1 to $N$ starting from the leftmost node. We assume that each node has a finite capacity. Let $K_{i}$ be the maximum capacity of node 


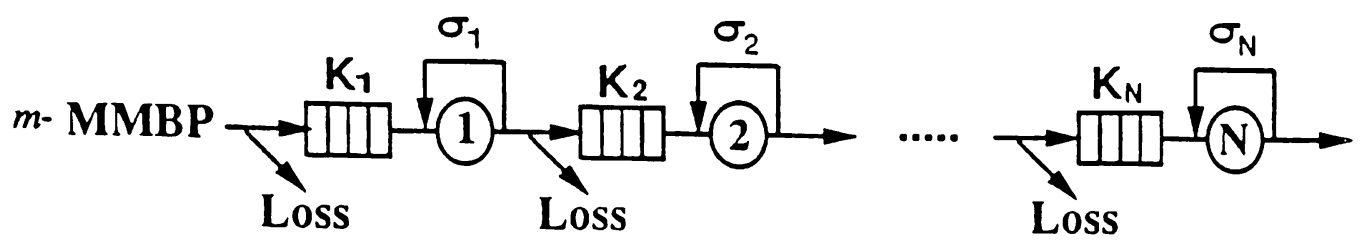

Figure 1: An open tandem queueing network under investigation

$i, i=1,2, \cdots, N$. A cell enters a node if it arrives at a time when the node is not full. Otherwise, it gets lost. The arrival process to the first node is assumed to be an $m$-MMBP. For each node $i$, the service time is assumed to be geometrically distributed with probability $\sigma_{i}$. We note that the $N$ servers are not synchronized. That is, the service slots of a server begin at a different time than the service slots of the other servers. However, all service slots of all servers are equal. Finally, we assume that cells in a node are served in a FIFO manner.

The approximation algorithm decomposes the queueing network into individual nodes, and each node is analyzed in isolation. Let us consider node $i$. We can obtain the the queue length distribution and the cell loss probability at node $i$. Using the fitting model described in section 4 , we can then obtain the transition probability matrix $P_{\text {est }}$ and $\Lambda_{\text {est }}$ of an $m$-MMBP which characterizes approximately the departure process of node $i$. This MMBP becomes the arrival process to the next down-stream node $i+1$. Since the arrival process to node $i+1$ is modeled as an $m$-MMBP, node $i+1$ can also be analyzed as an $m$-MMBP/Geo/1/ $K_{i+1}$ queue. In this manner, we can analyze all queues individually starting from the first node and proceeding sequentially to the last node. A summary of the algorithm is given below. step $0:$ Set $i=1$.

step 1: Obtain the queue length distribution and the cell loss probability at node $i$. If $i<N$, go to step 2. Else, stop.

step 2: Using one of the four rules, define $S_{i}, i=1,2, \cdots, m$, and then compute $P_{\text {est }}$ and $\Lambda_{\text {est }}$.

step 3 : Set $i=i+1$ and go to step 1 .

The accuracy of the approximation algorithm was tested by analyzing a 10 node tandem configuration. Two different examples were considered, one corresponding to a case of a 4MMBP as input traffic to the first node and the other to a case of an 8-MMBP as input traffic. 
The input traffic in both examples is bursty and strongly correlated. The characteristics of the arrival process to the first node for the two examples are given in Table 7 . The values of $K_{i}$ and $\sigma_{i}$ are: $K_{i}=8$ and $\sigma_{i}=0.1$ for $i=1, \cdots, 10$. The approximation results were compared against simulation data in Figures 2 to 9 . In particular, figures 2 to 5 are for example 1, and figures 6 to 9 for example 2 .

The approximate results were obtained using Rule 4 of the fitting method. In Figure 2 we give the queue length distribution and corresponding absolute errors for nodes 2, 5, and 10. In Figure 3 we give the $\operatorname{Pr}\{$ empty $\}, \operatorname{Pr}\{$ full $\}$, and cell loss and corresponding absolute errors for each queue. In Figure 4 we give the squared coefficient of variation of the interdeparture time and corresponding relative errors for each node. Finally, in Figure 5 the throughput and the autocorrelation coefficient of the interdeparture time for lag 1 and corresponding relative errors for each node are given. We note that the confidence intervals were not plotted in certain graphs as they were extremely small. The approximate results for example 2, given in Figures 6 to 9, are presented in the same way as in example 1.

\section{Conclusion}

In this paper, we proposed a tractable model for characterizing the interdeparture time of a discrete-time $m$-MMBP $/ \mathrm{Geo} / 1 / \mathrm{K}$ queue by an $m$-MMBP for $m>2$. We applied this model to the analysis of a tandem configuration of discrete-time finite capacity queues with a bursty and correlated input traffic and customer loss. It is shown that this model gives a satisfactory accuracy. 


\begin{tabular}{|c|c|c|c|c|c|c|c|}
\hline \multirow[b]{2}{*}{$m$} & \multirow{2}{*}{$\begin{array}{c}\text { Case } \\
\text { No } \\
\end{array}$} & \multicolumn{5}{|c|}{ Characteristics of Process } & \multirow[b]{2}{*}{ n } \\
\hline & & $\mathrm{A} / \mathrm{D}$ & $\rho$ & $C^{2}$ & $\psi(1)$ & $\phi(1)$ & \\
\hline \multirow{16}{*}{4} & \multirow[b]{2}{*}{1} & $\overline{\overline{\mathbf{A}}}$ & $7.04502 \mathrm{e}-1$ & $8.48055 \mathrm{e}+1$ & $\overline{4.94955 \mathrm{e}-1}$ & $\overline{8.93024 \mathrm{e}-1}$ & \multirow[b]{2}{*}{5000} \\
\hline & & $\mathrm{D}$ & $6.53881 \mathrm{e}-1$ & $7.87018 \mathrm{e}+1$ & $4.94501 \mathrm{e}-1$ & $7.05578 \mathrm{e}-1$ & \\
\hline & \multirow[b]{2}{*}{2} & $\overline{\mathbf{A}}$ & $7.94769 \mathrm{e}-1$ & $6.16660 \mathrm{e}+1$ & $3.06672 \mathrm{e}-2$ & $9.03532 \mathrm{e}-1$ & \multirow[b]{2}{*}{5000} \\
\hline & & $\bar{D}$ & $7.33192 \mathrm{e}-1$ & $5.56030 \mathrm{e}+1$ & $3.00801 \mathrm{e}-2$ & $6.18375 e-1$ & \\
\hline & \multirow[b]{2}{*}{3} & $\mathbf{A}$ & $7.02913 e-1$ & $6.52806 \mathrm{e}-1$ & $4.10138 \mathrm{e}-1$ & $2.72550 \mathrm{e}-1$ & \multirow[b]{2}{*}{74} \\
\hline & & $\overline{\mathrm{D}}$ & $7.00076 \mathrm{e}-1$ & $6.33676 \mathrm{e}-1$ & $3.82234 \mathrm{e}-1$ & $2.51222 \mathrm{e}-1$ & \\
\hline & \multirow[b]{2}{*}{4} & $\mathbf{A}$ & $8.13067 \mathrm{e}-1$ & $2.19952 \mathrm{e}-1$ & $7.50124 \mathrm{e}-2$ & $6.52405 \mathrm{e}-2$ & \multirow[b]{2}{*}{48} \\
\hline & & $\overline{\mathrm{D}}$ & $8.06426 \mathrm{e}-1$ & $2.23112 \mathrm{e}-1$ & $6.61526 \mathrm{e}-2$ & $5.56390 \mathrm{e}-2$ & \\
\hline & \multirow[b]{2}{*}{5} & $\overline{\mathbf{A}}$ & $9.53333 \mathrm{e}-2$ & $6.23655 \mathrm{e}+1$ & $4.78656 \mathrm{e}-1$ & $2.09993 \mathrm{e}-1$ & \multirow[b]{2}{*}{5000} \\
\hline & & $\mathrm{D}$ & $9.53333 \mathrm{e}-2$ & $6.23654 \mathrm{e}+1$ & $4.78657 \mathrm{e}-1$ & $2.09990 \mathrm{e}-1$ & \\
\hline & \multirow[b]{2}{*}{6} & $\bar{A}$ & $1.00822 \mathrm{e}-1$ & $5.84364 \mathrm{e}+1$ & $5.07200 \mathrm{e}-2$ & $5.60806 \mathrm{e}-2$ & \multirow[b]{2}{*}{5000} \\
\hline & & $\mathrm{D}$ & $1.00822 \mathrm{e}-1$ & $5.84354 \mathrm{e}+1$ & $5.07274 \mathrm{e}-2$ & $5.60713 \mathrm{e}-2$ & \\
\hline & \multirow[b]{2}{*}{7} & $\bar{A}$ & $9.53240 \mathrm{e}-2$ & $4.72397 \mathrm{e}+0$ & $4.02358 \mathrm{e}-1$ & $4.96824 \mathrm{e}-1$ & \multirow[b]{2}{*}{1362} \\
\hline & & $\bar{D}$ & $9.53198 \mathrm{e}-2$ & $4.72342 \mathrm{e}+0$ & $4.02352 \mathrm{e}-1$ & $4.96401 \mathrm{e}-1$ & \\
\hline & \multirow[b]{2}{*}{8} & $\mathbf{A}$ & $9.83090 \mathrm{e}-2$ & $9.89495 \mathrm{e}-1$ & $6.94780 \mathrm{e}-3$ & $2.83261 \mathrm{e}-2$ & \\
\hline & & $\mathrm{D}$ & $9.83090 \mathrm{e}-2$ & $9.88872 \mathrm{e}-1$ & $7.15267 \mathrm{e}-3$ & $2.64616 \mathrm{e}-2$ & 447 \\
\hline & & $\overline{\overline{\mathrm{A}}}$ & $6.17250 \mathrm{e}-1$ & $6.82982 \mathrm{e}+1$ & $4.33299 \mathrm{e}-1$ & $\overline{7.95908 \mathrm{e}-1}$ & \\
\hline & 9 & $\bar{D}$ & $5.92269 \mathrm{e}-1$ & $6.53567 e+1$ & $4.33020 \mathrm{e}-1$ & $7.07396 \mathrm{e}-1$ & 5000 \\
\hline & & $\mathbf{A}$ & $6.68300 \mathrm{e}-1$ & $6.66719 \mathrm{e}+1$ & $8.43551 \mathrm{e}-2$ & $8.70646 \mathrm{e}-1$ & \\
\hline & 10 & $\overline{\mathrm{D}}$ & $6.23634 \mathrm{e}-1$ & $6.12280 \mathrm{e}+1$ & $8.41053 \mathrm{e}-2$ & $6.91237 \mathrm{e}-1$ & 5000 \\
\hline & & $\bar{A}$ & $8.32259 \mathrm{e}-1$ & $3.55867 \mathrm{e}-1$ & $4.13766 \mathrm{e}-1$ & $3.24114 \mathrm{e}-1$ & \\
\hline & 11 & $\bar{D}$ & $7.71606 \mathrm{e}-1$ & $3.65534 \mathrm{e}-1$ & $2.97862 \mathrm{e}-1$ & $1.68523 \mathrm{e}-1$ & 51 \\
\hline & & $\bar{A}$ & $7.43093 \mathrm{e}-1$ & $2.89934 \mathrm{e}-1$ & $3.34737 \mathrm{e}-2$ & $5.36456 \mathrm{e}-2$ & \\
\hline & 12 & $\overline{\mathrm{D}}$ & $7.43015 \mathrm{e}-1$ & $2.80711 \mathrm{e}-1$ & $2.57795 \mathrm{e}-2$ & $3.54218 \mathrm{e}-2$ & 42 \\
\hline 6 & & $\mathrm{~A}$ & $7.91780 \mathrm{e}-2$ & $5.65617 \mathrm{e}+1$ & $4.83828 \mathrm{e}-1$ & $2.33293 \mathrm{e}-1$ & \\
\hline & 13 & $\overline{\mathrm{D}}$ & $7.91780 \mathrm{e}-2$ & $5.65616 \mathrm{e}+1$ & $4.83829 \mathrm{e}-1$ & $2.33290 \mathrm{e}-1$ & 5000 \\
\hline & & $\mathrm{A}$ & $9.57819 \mathrm{e}-2$ & $8.08826 \mathrm{e}+1$ & $8.84888 \mathrm{e}-2$ & $1.17192 \mathrm{e}-1$ & \\
\hline & 14 & $\bar{D}$ & $9.57819 \mathrm{e}-2$ & $8.08812 \mathrm{e}+1$ & $8.84973 \mathrm{e}-2$ & $1.17169 \mathrm{e}-1$ & 5000 \\
\hline & & $\bar{A}$ & $9.94214 \mathrm{e}-2$ & $4.63172 \mathrm{e}+0$ & $4.02234 \mathrm{e}-1$ & $2.18913 \mathrm{e}-1$ & \\
\hline & 15 & $\bar{D}$ & $9.94214 \mathrm{e}-2$ & $4.63171 \mathrm{e}+0$ & $4.02235 \mathrm{e}-1$ & $2.18907 \mathrm{e}-1$ & 1444 \\
\hline & & $\bar{A}$ & $9.45390 \mathrm{e}-2$ & $9.33600 \mathrm{e}-1$ & $2.49003 \mathrm{e}-3$ & $9.05005 \mathrm{e}-3$ & \\
\hline & 16 & $\bar{D}$ & $9.45390 \mathrm{e}-2$ & $9.33413 \mathrm{e}-1$ & $2.55498 \mathrm{e}-3$ & $8.44410 \mathrm{e}-3$ & 360 \\
\hline & & $\overline{\overline{\mathrm{A}}}$ & $7.30360 \mathrm{e}-1$ & $6.31614 \mathrm{e}+1$ & $4.90982 \mathrm{e}-1$ & $7.64792 \mathrm{e}-1$ & \\
\hline & 17 & $\bar{D}$ & $6.96164 \mathrm{e}-1$ & $6.01946 \mathrm{e}+1$ & $4.90599 \mathrm{e}-1$ & $6.40591 \mathrm{e}-1$ & 5000 \\
\hline & & $\bar{A}$ & $8.29750 \mathrm{e}-1$ & $1.07534 \mathrm{e}+2$ & $9.59465 \mathrm{e}-2$ & $4.50569 \mathrm{e}-1$ & \\
\hline & 18 & $\bar{D}$ & $8.05258 \mathrm{e}-1$ & $1.04224 \mathrm{e}+2$ & $9.58696 \mathrm{e}-2$ & $3.70655 \mathrm{e}-1$ & 5000 \\
\hline & & $\mathbf{A}$ & $8.17355 \mathrm{e}-1$ & $9.97370 \mathrm{e}-1$ & $4.06925 \mathrm{e}-1$ & $4.99108 \mathrm{e}-1$ & \\
\hline & 19 & $\overline{\mathrm{D}}$ & $7.78244 \mathrm{e}-1$ & $9.69906 \mathrm{e}-1$ & $3.84241 \mathrm{e}-1$ & $3.69717 \mathrm{e}-1$ & 155 \\
\hline & & $A$ & $7.10103 \mathrm{e}-1$ & $2.95436 \mathrm{e}-1$ & $3.93833 \mathrm{e}-3$ & $8.24199 \mathrm{e}-3$ & \\
\hline & 20 & $\bar{D}$ & $7.10089 \mathrm{e}-1$ & $2.94141 \mathrm{e}-1$ & $3.27816 \mathrm{e}-3$ & $5.77316 e-3$ & 32 \\
\hline 8 & & $\bar{A}$ & $9.99386 \mathrm{e}-2$ & $5.48128 \mathrm{e}+1$ & $4.49337 \mathrm{e}-1$ & $1.00892 \mathrm{e}-1$ & \\
\hline & 21 & $\mathrm{D}$ & $9.99386 \mathrm{e}-2$ & $5.48126 \mathrm{e}+1$ & $4.49338 \mathrm{e}-1$ & $1.00890 \mathrm{e}-1$ & 5000 \\
\hline & & $\mathrm{A}$ & $9.34750 \mathrm{e}-2$ & $5.85668 \mathrm{e}+1$ & $7.60631 \mathrm{e}-2$ & $7.57599 \mathrm{e}-2$ & \\
\hline & 22 & $\overline{\mathrm{D}}$ & $9.34750 \mathrm{e}-2$ & $5.85659 \mathrm{e}+1$ & $7.60709 \mathrm{e}-2$ & $7.57464 \mathrm{e}-2$ & 5000 \\
\hline & & $\bar{A}$ & $7.95309 \mathrm{e}-2$ & $6.06512 \mathrm{e}+0$ & $4.00097 \mathrm{e}-1$ & $8.78801 \mathrm{e}-2$ & \\
\hline & 23 & $\overline{\mathrm{D}}$ & $7.95309 \mathrm{e}-2$ & $6.06505 e+0$ & $4.00102 \mathrm{e}-1$ & $8.78642 \mathrm{e}-2$ & 3516 \\
\hline & & $\overline{\mathrm{A}}$ & $9.80699 \mathrm{e}-2$ & $9.37557 \mathrm{e}-1$ & $1.44772 \mathrm{e}-3$ & $1.06972 \mathrm{e}-2$ & \\
\hline & 24 & $\overline{\mathrm{D}}$ & $9.80699 \mathrm{e}-2$ & $9.37317 \mathrm{e}-1$ & $1.54479 \mathrm{e}-3$ & $1.00347 \mathrm{e}-2$ & 346 \\
\hline
\end{tabular}

A : Arrival process

D : Departure process

Table 1: The characteristics of arrival process and departure process $(\sigma=0.1, \mathrm{~K}=8)$ 


\begin{tabular}{|c|c|c|c|c|c|}
\hline \multirow{2}{*}{$\begin{array}{c}\text { Case } \\
\text { No }\end{array}$} & \multirow[b]{2}{*}{ Rule } & \multicolumn{4}{|c|}{ The Fitted MMBP } \\
\hline & & $C_{\text {est }}^{2}$ & $\psi_{\text {est }}(1) / \epsilon_{\psi}(n)$ & $\phi_{\text {est }}(1) / \epsilon_{\phi}(n)$ & $\epsilon_{D}(n)$ \\
\hline \multirow{6}{*}{1} & 1 & $7.820895 \mathrm{e}+1$ & $4.942602 \mathrm{e}-1 / 7.108599 \mathrm{e}+0$ & $7.055996 \mathrm{e}-1 / 3.319292 \mathrm{e}+1$ & $6.374898 \mathrm{e}-5$ \\
\hline & 2 & $7.820895 \mathrm{e}+1$ & $4.942602 \mathrm{e}-1 / 7.108599 \mathrm{e}+0$ & $7.055996 \mathrm{e}-1 / 3.319292 \mathrm{e}+1$ & $6.374898 \mathrm{e}-5$ \\
\hline & 3 & $7.820890 \mathrm{e}+1$ & $4.942600 \mathrm{e}-1 / 7.472899 \mathrm{e}+0$ & $7.055842 \mathrm{e}-1 / 3.134189 \mathrm{e}+1$ & $4.621978 \mathrm{e}-5$ \\
\hline & 4 & $7.820890 \mathrm{e}+1$ & $4.942600 \mathrm{e}-1 / 7.472899 \mathrm{e}+0$ & $7.055842 \mathrm{e}-1 / 3.134189 \mathrm{e}+1$ & $4.621978 \mathrm{e}-5$ \\
\hline & si & $7.820875 \mathrm{e}+1$ & $4.942585 \mathrm{e}-1 / 6.235466 \mathrm{e}+0$ & $7.055652 \mathrm{e}-1 / 2.862155 \mathrm{e}+1$ & $3.562272 \mathrm{e}-5$ \\
\hline & s2 & $7.773362 \mathrm{e}+1$ & $4.945110 \mathrm{e}-1 / 2.836749 \mathrm{e}-1$ & $7.055348 \mathrm{e}-1 / 3.997362 \mathrm{e}+0$ & $6.161486 \mathrm{e}-5$ \\
\hline \multirow{6}{*}{2} & $\overline{\overline{1}}$ & $\overline{3.254692 \mathrm{e}+1}$ & $2.127297 \mathrm{e}-1 / 5.175811 \mathrm{e}-1$ & $6.150905 \mathrm{e}-1 / 3.117162 \mathrm{e}+1$ & $2.404048 \mathrm{e}-3$ \\
\hline & 2 & $3.254692 \mathrm{e}+1$ & $2.127297 \mathrm{e}-1 / 5.175811 \mathrm{e}-1$ & $6.150905 \mathrm{e}-1 / 3.117162 \mathrm{e}+1$ & $2.404048 \mathrm{e}-3$ \\
\hline & 3 & $3.253830 \mathrm{e}+1$ & $2.121722 \mathrm{e}-1 / 5.408041 \mathrm{e}-1$ & $6.149147 \mathrm{e}-1 / 3.691177 \mathrm{e}+1$ & $2.393510 \mathrm{e}-3$ \\
\hline & 4 & $3.253830 \mathrm{e}+1$ & $2.121722 \mathrm{e}-1 / 5.408041 \mathrm{e}-1$ & $6.149147 \mathrm{e}-1 / 3.691177 \mathrm{e}+1$ & $2.393510 \mathrm{e}-3$ \\
\hline & s1 & $5.562422 \mathrm{e}+1$ & $-1.69289 \mathrm{e}-4 / 2.107519 \mathrm{e}-1$ & $6.188440 \mathrm{e}-1 / 4.388336 \mathrm{e}+1$ & $2.655174 \mathrm{e}-4$ \\
\hline & $\mathrm{s} 2$ & $5.103013 \mathrm{e}+1$ & $3.920893 \mathrm{e}-2 / 1.748799 \mathrm{e}-1$ & $6.174528 \mathrm{e}-1 / 3.307216 \mathrm{e}+1$ & $7.878752 \mathrm{e}-4$ \\
\hline \multirow{6}{*}{3} & $\overline{1}$ & $6.541278 \mathrm{e}-1$ & $3.486807 \mathrm{e}-1 / 1.186206 \mathrm{e}+0$ & $2.568030 \mathrm{e}-1 / 1.683327 \mathrm{e}+0$ & $\overline{4.594627 \mathrm{e}-3}$ \\
\hline & 2 & $6.350515 \mathrm{e}-1$ & $3.415923 \mathrm{e}-1 / 9.586119 \mathrm{e}-1$ & $2.488842 \mathrm{e}-1 / 1.544829 \mathrm{e}+0$ & $3.300825 \mathrm{e}-3$ \\
\hline & 3 & $6.163353 \mathrm{e}-1$ & $3.299858 \mathrm{e}-1 / 1.004895 \mathrm{e}+0$ & $2.410468 \mathrm{e}-1 / 1.863798 \mathrm{e}+0$ & $7.186524 \mathrm{e}-3$ \\
\hline & 4 & $6.120884 \mathrm{e}-1$ & $3.288941 \mathrm{e}-1 / 8.532492 \mathrm{e}-1$ & $2.390792 \mathrm{e}-1 / 1.690157 \mathrm{e}+0$ & $8.635246 \mathrm{e}-3$ \\
\hline & s1 & $6.397960 \mathrm{e}-1$ & $3.375681 \mathrm{e}-1 / 1.856755 \mathrm{e}+0$ & $2.518752 \mathrm{e}-1 / 3.006204 \mathrm{e}+0$ & $2.089383 \mathrm{e}-3$ \\
\hline & $\mathrm{s} 2$ & $6.095815 \mathrm{e}-1$ & $3.293928 \mathrm{e}-1 / 5.870004 \mathrm{e}-1$ & $2.378064 \mathrm{e}-1 / 1.335847 \mathrm{e}+0$ & $9.561662 \mathrm{e}-3$ \\
\hline \multirow{6}{*}{4} & $\overline{1}$ & $2.266934 \mathrm{e}-1$ & $6.964717 \mathrm{e}-2 / 1.396481 \mathrm{e}+0$ & $6.132903 \mathrm{e}-2 / 8.724712 \mathrm{e}-1$ & $2.920795 \mathrm{e}-3$ \\
\hline & 2 & $2.239230 \mathrm{e}-1$ & $6.720116 \mathrm{e}-2 / 4.269149 \mathrm{e}-1$ & $5.723105 \mathrm{e}-2 / 2.234545 \mathrm{e}-1$ & $8.860163 \mathrm{e}-4$ \\
\hline & 3 & $2.233434 \mathrm{e}-1$ & $6.650185 \mathrm{e}-2 / 9.099756 \mathrm{e}-2$ & $5.627589 \mathrm{e}-2 / 4.202177 \mathrm{e}-2$ & $4.093240 \mathrm{e}-4$ \\
\hline & 4 & $2.232187 \mathrm{e}-1$ & $6.633548 \mathrm{e}-2 / 2.170542 \mathrm{e}-2$ & $5.607247 \mathrm{e}-2 / 1.027363 \mathrm{e}-2$ & $3.131103 \mathrm{e}-4$ \\
\hline & s1 & $2.231635 \mathrm{e}-1$ & $6.625188 \mathrm{e}-2 / 2.461651 \mathrm{e}-3$ & $5.598531 \mathrm{e}-2 / 1.250900 \mathrm{e}-2$ & $2.742483 \mathrm{e}-4$ \\
\hline & s2 & $2.231635 \mathrm{e}-1$ & $6.625188 \mathrm{e}-2 / 2.461651 \mathrm{e}-3$ & $5.598531 \mathrm{e}-2 / 1.250900 \mathrm{e}-2$ & $2.742483 \mathrm{e}-4$ \\
\hline
\end{tabular}

s1 : searching for the smallest $\epsilon_{D}(n)$

s2 : searching for the smallest $\epsilon_{\psi}(n)$

Table 2: Validation results (4-MMBP) 


\begin{tabular}{|c|c|c|c|c|c|}
\hline \multirow{2}{*}{$\begin{array}{c}\text { Case } \\
\text { No } \\
\end{array}$} & \multirow[b]{2}{*}{ Rule } & \multicolumn{4}{|c|}{ The Fitted MMBP } \\
\hline & & $C_{\text {est }}^{2}$ & $\psi_{\text {est }}(1) / \epsilon_{\psi}(n)$ & $\phi_{\text {est }}(1) / \epsilon_{\phi}(n)$ & $\epsilon_{D}(n)$ \\
\hline \multirow{6}{*}{5} & 1 & $6.229784 \mathrm{e}+1$ & $4.785514 \mathrm{e}-1 / 2.522724 \mathrm{e}+1$ & $2.109793 \mathrm{e}-1 / 5.695838 \mathrm{e}+2$ & $2.427702 \mathrm{e}-3$ \\
\hline & 2 & $6.229784 \mathrm{e}+1$ & $4.785514 \mathrm{e}-1 / 2.522724 \mathrm{e}+1$ & $2.109793 \mathrm{e}-1 / 5.695838 \mathrm{e}+2$ & $2.427702 \mathrm{e}-3$ \\
\hline & 3 & $6.229784 \mathrm{e}+1$ & $4.785514 \mathrm{e}-1 / 2.522724 \mathrm{e}+1$ & $2.109793 \mathrm{e}-1 / 5.695838 \mathrm{e}+2$ & $2.427702 \mathrm{e}-3$ \\
\hline & 4 & $6.229655 e+1$ & $4.785791 \mathrm{e}-1 / 2.006881 \mathrm{e}+1$ & $2.103362 \mathrm{e}-1 / 4.060117 \mathrm{e}+2$ & $8.449557 \mathrm{e}-4$ \\
\hline & s1 & $6.229557 e+1$ & $4.786113 \mathrm{e}-1 / 1.264112 \mathrm{e}+0$ & $2.099898 \mathrm{e}-1 / 6.299687 \mathrm{e}+0$ & $1.093209 \mathrm{e}-5$ \\
\hline & $\mathrm{s} 2$ & $6.229090 e+1$ & $4.786651 \mathrm{e}-1 / 3.679730 \mathrm{e}-2$ & $2.099874 \mathrm{e}-1 / 1.367556 \mathrm{e}-1$ & $1.353420 \mathrm{e}-5$ \\
\hline \multirow{6}{*}{6} & 1 & $5.753743 \mathrm{e}+1$ & $5.760565 \mathrm{e}-2 / 9.323817 \mathrm{e}-2$ & $5.709786 \mathrm{e}-2 / 5.650215 \mathrm{e}+0$ & $4.109714 \mathrm{e}-3$ \\
\hline & 2 & $5.753743 \mathrm{e}+1$ & $5.760565 \mathrm{e}-2 / 9.323817 \mathrm{e}-2$ & $5.709786 \mathrm{e}-2 / 5.650215 \mathrm{e}+0$ & $4.109714 \mathrm{e}-3$ \\
\hline & 3 & $5.753743 \mathrm{e}+1$ & $5.760565 \mathrm{e}-2 / 9.323817 \mathrm{e}-2$ & $5.709786 \mathrm{e}-2 / 5.650215 \mathrm{e}+0$ & $4.109714 \mathrm{e}-3$ \\
\hline & 4 & $5.752875 \mathrm{e}+1$ & $5.756643 \mathrm{e}-2 / 1.052277 \mathrm{e}-2$ & $5.607758 \mathrm{e}-2 / 2.333762 \mathrm{e}-1$ & $1.311164 \mathrm{e}-4$ \\
\hline & s1 & $5.752863 e+1$ & $5.756580 \mathrm{e}-2 / 1.077701 \mathrm{e}-2$ & $5.606256 \mathrm{e}-2 / 2.052356 \mathrm{e}-2$ & $1.119158 \mathrm{e}-4$ \\
\hline & s2 & $5.752875 e+1$ & $5.756643 \mathrm{e}-2 / 1.052277 \mathrm{e}-2$ & $5.607758 \mathrm{e}-2 / 2.333762 \mathrm{e}-1$ & $1.311164 \mathrm{e}-4$ \\
\hline \multirow{6}{*}{7} & 1 & $4.719355 \mathrm{e}+0$ & $4.004165 \mathrm{e}-1 / 4.268435 \mathrm{e}+1$ & $4.965898 \mathrm{e}-1 / 1.345251 \mathrm{e}+2$ & $7.713123 \mathrm{e}-4$ \\
\hline & 2 & $4.719355 \mathrm{e}+0$ & $4.004165 \mathrm{e}-1 / 4.268435 \mathrm{e}+1$ & $4.965898 \mathrm{e}-1 / 1.345251 \mathrm{e}+2$ & $7.713123 \mathrm{e}-4$ \\
\hline & 3 & $4.719355 \mathrm{e}+0$ & $4.004165 \mathrm{e}-1 / 4.268435 \mathrm{e}+1$ & $4.965898 \mathrm{e}-1 / 1.345251 \mathrm{e}+2$ & $7.713123 \mathrm{e}-4$ \\
\hline & 4 & $4.715778 \mathrm{e}+0$ & $4.020026 \mathrm{e}-1 / 7.991337 \mathrm{e}+0$ & $4.961588 \mathrm{e}-1 / 2.011135 \mathrm{e}+1$ & $8.301300 \mathrm{e}-4$ \\
\hline & s1 & $4.718322 \mathrm{e}+0$ & $4.005189 \mathrm{e}-1 / 4.114259 \mathrm{e}+1$ & $4.965071 \mathrm{e}-1 / 1.282323 \mathrm{e}+2$ & $7.194884 \mathrm{e}-4$ \\
\hline & s2 & $4.714406 \mathrm{e}+0$ & $4.021645 \mathrm{e}-1 / 2.840170 \mathrm{e}-2$ & $4.960547 \mathrm{e}-1 / 6.428578 \mathrm{e}-1$ & $1.008437 \mathrm{e}-3$ \\
\hline \multirow{6}{*}{8} & 1 & $9.849355 \mathrm{e}-1$ & $6.981917 \mathrm{e}-3 / 2.572793 \mathrm{e}-4$ & $2.677861 \mathrm{e}-2 / 3.137776 \mathrm{e}-3$ & $3.671594 \mathrm{e}-3$ \\
\hline & 2 & $9.849355 \mathrm{e}-1$ & $6.981917 \mathrm{e}-3 / 2.572793 \mathrm{e}-4$ & $2.677861 \mathrm{e}-2 / 3.137776 \mathrm{e}-3$ & $3.671594 \mathrm{e}-3$ \\
\hline & 3 & $9.849355 \mathrm{e}-1$ & $6.981917 \mathrm{e}-3 / 2.572793 \mathrm{e}-4$ & $2.677861 \mathrm{e}-2 / 3.137776 \mathrm{e}-3$ & $3.671594 \mathrm{e}-3$ \\
\hline & 4 & $9.791122 \mathrm{e}-1$ & $6.228441 \mathrm{e}-3 / 1.274031 \mathrm{e}-3$ & $2.490342 \mathrm{e}-2 / 6.894808 \mathrm{e}-3$ & $7.596449 \mathrm{e}-3$ \\
\hline & s1 & $9.849355 \mathrm{e}-1$ & $6.981917 \mathrm{e}-3 / 2.572793 \mathrm{e}-4$ & $2.677861 \mathrm{e}-2 / 3.137776 \mathrm{e}-3$ & $3.671594 \mathrm{e}-3$ \\
\hline & s2 & $9.849355 \mathrm{e}-1$ & $6.981917 \mathrm{e}-3 / 2.572793 \mathrm{e}-4$ & $2.677861 \mathrm{e}-2 / 3.137776 \mathrm{e}-3$ & $3.671594 \mathrm{e}-3$ \\
\hline
\end{tabular}

s1: searching for the smallest $\epsilon_{D}(n)$

s2 : searching for the smallest $\epsilon_{\psi}(n)$

Table 3: Validation results (4-MMBP) 


\begin{tabular}{|c|c|c|c|c|c|}
\hline \multirow{2}{*}{$\begin{array}{c}\text { Case } \\
\text { No }\end{array}$} & \multirow[b]{2}{*}{ Rule } & \multicolumn{4}{|c|}{ The Fitted MMBP } \\
\hline & & $C_{\text {est }}^{2}$ & $\psi_{\text {est }}(1) / \epsilon_{\psi}(n)$ & $\phi_{\text {est }}(1) / \epsilon_{\phi}(n)$ & $\overline{\epsilon_{D}(n)}$ \\
\hline \multirow{4}{*}{9} & 1 & $5.932555 \mathrm{e}+1$ & $4.398221 \mathrm{e}-1 / 4.393352 \mathrm{e}-1$ & $7.072328 \mathrm{e}-1 / 1.026827 \mathrm{e}+1$ & $8.307565 \mathrm{e}-4$ \\
\hline & 2 & $5.932542 \mathrm{e}+1$ & $4.398214 \mathrm{e}-1 / 4.313413 \mathrm{e}-1$ & $7.071082 \mathrm{e}-1 / 9.771340 \mathrm{e}+0$ & $7.712248 \mathrm{e}-4$ \\
\hline & 3 & $5.932481 \mathrm{e}+1$ & $4.398192 \mathrm{e}-1 / 4.693607 \mathrm{e}-1$ & $7.069645 \mathrm{e}-1 / 4.348634 \mathrm{e}+0$ & $7.067268 \mathrm{e}-4$ \\
\hline & 4 & $5.932481 \mathrm{e}+1$ & $4.398192 \mathrm{e}-1 / 4.377491 \mathrm{e}-1$ & $7.069639 \mathrm{e}-1 / 9.962881 \mathrm{e}+0$ & $7.061843 \mathrm{e}-4$ \\
\hline \multirow{4}{*}{10} & 1 & $3.815703 \mathrm{e}+1$ & $2.382285 \mathrm{e}-1 / 9.330941 \mathrm{e}-1$ & $6.896936 \mathrm{e}-1 / 9.695458 \mathrm{e}+1$ & $4.422096 \mathrm{e}-3$ \\
\hline & 2 & $3.814546 \mathrm{e}+1$ & $2.380240 \mathrm{e}-1 / 8.971473 \mathrm{e}-1$ & $6.883401 \mathrm{e}-1 / 9.325250 \mathrm{e}+1$ & $4.083700 \mathrm{e}-3$ \\
\hline & 3 & $3.812950 \mathrm{e}+1$ & $2.372888 \mathrm{e}-1 / 8.594288 \mathrm{e}-1$ & $6.874786 \mathrm{e}-1 / 9.230779 \mathrm{e}+1$ & $3.867670 \mathrm{e}-3$ \\
\hline & 4 & $2.929479 \mathrm{e}+1$ & $2.957000 \mathrm{e}-1 / 9.474137 \mathrm{e}-1$ & $6.841722 \mathrm{e}-1 / 7.918188 \mathrm{e}+1$ & $6.796293 \mathrm{e}-3$ \\
\hline \multirow{4}{*}{11} & $\overline{1}$ & $3.906664 \mathrm{e}-1$ & $2.828740 \mathrm{e}-1 / 7.517416 \mathrm{e}+0$ & $1.870197 \mathrm{e}-1 / 4.011179 \mathrm{e}+0$ & $1.096270 \mathrm{e}-2$ \\
\hline & 2 & $3.862804 \mathrm{e}-1$ & $2.872168 \mathrm{e}-1 / 1.908077 \mathrm{e}+0$ & $1.830951 \mathrm{e}-1 / 6.114975 \mathrm{e}-1$ & $8.713003 \mathrm{e}-3$ \\
\hline & 3 & $3.862804 \mathrm{e}-1$ & $2.872168 \mathrm{e}-1 / 1.908077 \mathrm{e}+0$ & $1.830951 \mathrm{e}-1 / 6.114975 \mathrm{e}-1$ & $8.713003 \mathrm{e}-3$ \\
\hline & 4 & $3.840173 \mathrm{e}-1$ & $2.857139 \mathrm{e}-1 / 1.255539 \mathrm{e}+0$ & $1.813354 \mathrm{e}-1 / 3.368670 \mathrm{e}-1$ & $7.713448 \mathrm{e}-3$ \\
\hline \multirow{4}{*}{12} & $\overline{1}$ & $2.779478 \mathrm{e}-1$ & $2.131528 \mathrm{e}-2 / 4.343614 \mathrm{e}-2$ & $3.357808 \mathrm{e}-2 / 5.221451 \mathrm{e}-2$ & $1.561405 \mathrm{e}-3$ \\
\hline & $\overline{2}$ & $2.734495 \mathrm{e}-1$ & $1.737667 \mathrm{e}-2 / 5.174847 \mathrm{e}-2$ & $2.666143 \mathrm{e}-2 / 7.064144 \mathrm{e}-2$ & $6.365878 \mathrm{e}-3$ \\
\hline & 3 & $2.718953 \mathrm{e}-1$ & $1.594708 \mathrm{e}-2 / 5.487398 \mathrm{e}-2$ & $2.422819 \mathrm{e}-2 / 7.720855 \mathrm{e}-2$ & $8.070459 \mathrm{e}-3$ \\
\hline & 4 & $2.714806 \mathrm{e}-1$ & $1.551518 \mathrm{e}-2 / 5.594759 \mathrm{e}-2$ & $2.358166 \mathrm{e}-2 / 7.920767 \mathrm{e}-2$ & $8.524128 \mathrm{e}-3$ \\
\hline \multirow{4}{*}{13} & 1 & $5.653155 \mathrm{e}+1$ & $4.837164 \mathrm{e}-1 / 3.708754 \mathrm{e}+1$ & $2.333046 \mathrm{e}-1 / 6.197055 \mathrm{e}+1$ & $5.792342 \mathrm{e}-5$ \\
\hline & 2 & $5.653155 \mathrm{e}+1$ & $4.837164 \mathrm{e}-1 / 3.708754 \mathrm{e}+1$ & $2.333046 \mathrm{e}-1 / 6.197055 \mathrm{e}+1$ & $5.792342 \mathrm{e}-5$ \\
\hline & 3 & $5.653155 e+1$ & $4.837164 e-1 / 3.708754 e+1$ & $2.333046 \mathrm{e}-1 / 6.197055 \mathrm{e}+1$ & $5.792342 \mathrm{e}-5$ \\
\hline & 4 & $5.653155 \mathrm{e}+1$ & $4.837164 \mathrm{e}-1 / 3.708754 \mathrm{e}+1$ & $2.333046 \mathrm{e}-1 / 6.197055 \mathrm{e}+1$ & $5.792342 \mathrm{e}-5$ \\
\hline \multirow{4}{*}{14} & 1 & $7.963806 \mathrm{e}+1$ & $9.507741 \mathrm{e}-2 / 7.425472 \mathrm{e}-2$ & $1.185766 \mathrm{e}-1 / 7.107207 \mathrm{e}+0$ & $\overline{4.631804 \mathrm{e}-3}$ \\
\hline & 2 & $7.963806 \mathrm{e}+1$ & $9.507741 \mathrm{e}-2 / 7.425472 \mathrm{e}-2$ & $1.185766 \mathrm{e}-1 / 7.107207 \mathrm{e}+0$ & $4.631804 \mathrm{e}-3$ \\
\hline & 3 & $7.963806 \mathrm{e}+1$ & $9.507741 \mathrm{e}-2 / 7.425472 \mathrm{e}-2$ & $1.185766 \mathrm{e}-1 / 7.107207 \mathrm{e}+0$ & $4.631804 \mathrm{e}-3$ \\
\hline & 4 & $7.963293 e+1$ & $9.505951 \mathrm{e}-2 / 1.521701 \mathrm{e}-2$ & $1.171816 \mathrm{e}-1 / 9.170844 \mathrm{e}-1$ & $2.218231 \mathrm{e}-4$ \\
\hline \multirow{4}{*}{15} & 1 & $4.633733 \mathrm{e}+0$ & $4.006433 \mathrm{e}-1 / 2.099859 \mathrm{e}+2$ & $2.210588 \mathrm{e}-1 / 7.420950 \mathrm{e}+1$ & $\overline{4.860401 \mathrm{e}-3}$ \\
\hline & 2 & $4.633292 \mathrm{e}+0$ & $4.006451 \mathrm{e}-1 / 2.008789 \mathrm{e}+2$ & $2.195182 \mathrm{e}-1 / 7.222203 \mathrm{e}+1$ & $1.298344 \mathrm{e}-3$ \\
\hline & 3 & $4.633292 \mathrm{e}+0$ & $4.006451 \mathrm{e}-1 / 2.008789 \mathrm{e}+2$ & $2.195182 \mathrm{e}-1 / 7.222203 \mathrm{e}+1$ & $1.298344 \mathrm{e}-3$ \\
\hline & 4 & $4.633194 \mathrm{e}+0$ & $4.006448 \mathrm{e}-1 / 1.796887 \mathrm{e}+2$ & $2.192593 \mathrm{e}-1 / 7.095634 \mathrm{e}+1$ & $8.011568 \mathrm{e}-4$ \\
\hline \multirow{4}{*}{16} & 1 & $9.316087 \mathrm{e}-1$ & $2.227383 \mathrm{e}-3 / 4.429887 \mathrm{e}-4$ & $8.461523 \mathrm{e}-3 / 1.493405 \mathrm{e}-3$ & $1.518952 \mathrm{e}-3$ \\
\hline & 2 & $9.316087 \mathrm{e}-1$ & $2.227383 \mathrm{e}-3 / 4.429887 \mathrm{e}-4$ & $8.461523 \mathrm{e}-3 / 1.493405 \mathrm{e}-3$ & $1.518952 \mathrm{e}-3$ \\
\hline & 3 & $9.316087 \mathrm{e}-1$ & $2.227383 \mathrm{e}-3 / 4.429887 \mathrm{e}-4$ & $8.461523 \mathrm{e}-3 / 1.493405 \mathrm{e}-3$ & $1.518952 \mathrm{e}-3$ \\
\hline & 4 & $9.303819 \mathrm{e}-1$ & $2.209184 \mathrm{e}-3 / 4.471112 \mathrm{e}-4$ & $7.923283 \mathrm{e}-3 / 2.143915 \mathrm{e}-3$ & $2.465133 \mathrm{e}-3$ \\
\hline
\end{tabular}

Table 4: Validation results (6-MMBP) 


\begin{tabular}{|c|c|c|c|c|c|}
\hline \multirow{2}{*}{$\begin{array}{c}\text { Case } \\
\text { No } \\
\end{array}$} & \multirow[b]{2}{*}{ Rule } & \multicolumn{4}{|c|}{ The Fitted MMBP } \\
\hline & & $C_{\text {est }}^{2}$ & $\psi_{\text {est }}(1) / \epsilon_{\psi}(n)$ & $\phi_{\text {est }}(1) / \epsilon_{\phi}(n)$ & $\epsilon_{D}(n)$ \\
\hline \multirow{4}{*}{17} & 1 & $948657 \mathrm{e}+1$ & $903757 \mathrm{e}-1 / 1.334909 \mathrm{e}+0$ & $6.412379 \mathrm{e}-1 / 2.949852 \mathrm{e}+1$ & $7.124755 \mathrm{e}-4$ \\
\hline & 2 & $5.948651 \mathrm{e}+1$ & $4.903756 \mathrm{e}-1 / 1.335757 \mathrm{e}+0$ & $6.411398 \mathrm{e}-1 / 2.951437 \mathrm{e}+1$ & $6.152184 \mathrm{e}-4$ \\
\hline & 3 & $5.948621 \mathrm{e}+1$ & $4.903746 \mathrm{e}-1 / 1.121537 \mathrm{e}+0$ & $6.407704 \mathrm{e}-1 / 2.599933 \mathrm{e}+1$ & $2.480347 e-4$ \\
\hline & 4 & $5.948624 \mathrm{e}+1$ & $4.903748 \mathrm{e}-1 / 1.399222 \mathrm{e}+0$ & $6.407761 \mathrm{e}-1 / 2.859624 \mathrm{e}+1$ & $2.533901 \mathrm{e}-4$ \\
\hline \multirow{4}{*}{18} & 1 & $494180 \mathrm{e}+1$ & $2.177577 \mathrm{e}-1 / 5.220951 \mathrm{e}-1$ & $3.731942 \mathrm{e}-1 / 9.371824 \mathrm{e}+1$ & $\overline{1.583751 \mathrm{e}-3}$ \\
\hline & 2 & $7.493898 \mathrm{e}+1$ & $2.177464 \mathrm{e}-1 / 5.075380 \mathrm{e}-1$ & $3.716318 \mathrm{e}-1 / 8.621757 \mathrm{e}+1$ & $7.328520 \mathrm{e}-4$ \\
\hline & 3 & $7.493728 \mathrm{e}+1$ & $2.177341 \mathrm{e}-1 / 4.291774 \mathrm{e}-1$ & $3.711346 \mathrm{e}-1 / 4.892270 \mathrm{e}+1$ & $4.521987 \mathrm{e}-4$ \\
\hline & 4 & $7.493685 \mathrm{e}+1$ & $2.177305 \mathrm{e}-1 / 3.915480 \mathrm{e}-1$ & $3.709903 \mathrm{e}-1 / 4.161391 \mathrm{e}+1$ & $3.713510 \mathrm{e}-4$ \\
\hline \multirow{4}{*}{19} & 1 & $0436 \mathrm{e}-1$ & $3.762244 \mathrm{e}-1 / 3.061540 \mathrm{e}+1$ & $3.741867 \mathrm{e}-1 / 1.584621 \mathrm{e}+1$ & $2.727315 \mathrm{e}-3$ \\
\hline & 2 & $9.728928 \mathrm{e}-1$ & $3.762579 \mathrm{e}-1 / 3.056597 \mathrm{e}+1$ & $3.721513 \mathrm{e}-1 / 1.560880 \mathrm{e}+1$ & $1.490520 \mathrm{e}-3$ \\
\hline & 3 & $9.720884 \mathrm{e}-1$ & $3.762198 \mathrm{e}-1 / 2.824072 \mathrm{e}+1$ & $3.704580 \mathrm{e}-1 / 1.370717 \mathrm{e}+1$ & $3.566171 \mathrm{e}-4$ \\
\hline & 4 & $9.657228 \mathrm{e}-1$ & $3.834915 \mathrm{e}-1 / 2.075293 \mathrm{e}+0$ & $3.694004 \mathrm{e}-1 / 8.120480 \mathrm{e}-1$ & $2.659875 \mathrm{e}-4$ \\
\hline \multirow{4}{*}{20} & 1 & $2.953151 \mathrm{e}-1$ & $4.991579 \mathrm{e}-3 / 5.178607 \mathrm{e}-3$ & $8.279300 \mathrm{e}-3 / 8.082236 \mathrm{e}-3$ & $2.266282 \mathrm{e}-3$ \\
\hline & 2 & $2.933574 \mathrm{e}-1$ & $2.767378 \mathrm{e}-3 / 2.766257 \mathrm{e}-3$ & $5.190251 \mathrm{e}-3 / 4.101290 \mathrm{e}-3$ & $5.218965 \mathrm{e}-4$ \\
\hline & 3 & $2.928728 \mathrm{e}-1$ & $2.217048 \mathrm{e}-3 / 4.438107 \mathrm{e}-3$ & $4.423395 \mathrm{e}-3 / 6.635751 \mathrm{e}-3$ & $1.117226 \mathrm{e}-3$ \\
\hline & 4 & $2.927032 \mathrm{e}-1$ & $2.009797 \mathrm{e}-3 / 5.125487 \mathrm{e}-3$ & $4.152025 \mathrm{e}-3 / 7.624655 \mathrm{e}-3$ & $1.329761 \mathrm{e}-3$ \\
\hline \multirow{4}{*}{21} & $\overline{1}$ & $472132 \mathrm{e}+1$ & $\overline{42 \mathrm{e}-1 / 4.850233 \mathrm{e}+0}$ & $1.027013 \mathrm{e}-1 / 1.062591 \mathrm{e}+2$ & $5.524205 \mathrm{e}-3$ \\
\hline & $\overline{2}$ & $5.471995 \mathrm{e}+1$ & $4.493142 \mathrm{e}-1 / 4.785242 \mathrm{e}+0$ & $1.017851 \mathrm{e}-1 / 1.023263 \mathrm{e}+2$ & $2.777210 \mathrm{e}-3$ \\
\hline & $\overline{3}$ & $5.471995 \mathrm{e}+1$ & $4.493142 \mathrm{e}-1 / 4.785242 \mathrm{e}+0$ & $1.017851 \mathrm{e}-1 / 1.023263 \mathrm{e}+2$ & $2.777210 \mathrm{e}-3$ \\
\hline & 4 & $5.471870 \mathrm{e}+1$ & $4.493199 \mathrm{e}-1 / 4.122544 \mathrm{e}+0$ & $1.012171 \mathrm{e}-1 / 7.887931 \mathrm{e}+1$ & $1.100623 \mathrm{e}-3$ \\
\hline \multirow{4}{*}{22} & 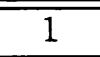 & $5.777564 \mathrm{e}+1$ & $8.203132 \mathrm{e}-2 / 8.577625 \mathrm{e}-2$ & $7.921775 \mathrm{e}-2 / 5.408996 \mathrm{e}+0$ & $1.017151 \mathrm{e}-2$ \\
\hline & 2 & $5.777564 \mathrm{e}+1$ & $8.203132 \mathrm{e}-2 / 8.577625 \mathrm{e}-2$ & $7.921775 \mathrm{e}-2 / 5.408996 \mathrm{e}+0$ & $1.017151 \mathrm{e}-2$ \\
\hline & 3 & $5.777564 \mathrm{e}+1$ & $132 \mathrm{e}-2 / 8.577625 \mathrm{e}-2$ & $7.921775 \mathrm{e}-2 / 5.408996 \mathrm{e}+0$ & $1.017151 \mathrm{e}-2$ \\
\hline & 4 & $5.776507 \mathrm{e}+1$ & $8.199957 \mathrm{e}-2 / 2.376408 \mathrm{e}-2$ & $7.579340 \mathrm{e}-2 / 1.217393 \mathrm{e}+0$ & $2.680668 \mathrm{e}-4$ \\
\hline \multirow{4}{*}{23} & 1 & $6.063560 \mathrm{e}+0$ & $3.993432 \mathrm{e}-1 / 1.201235 \mathrm{e}+0$ & $9.085193 \mathrm{e}-2 / 7.680528 \mathrm{e}+0$ & $\overline{8.943304 \mathrm{e}-3}$ \\
\hline & 2 & $6.063560 \mathrm{e}+0$ & $3.993432 \mathrm{e}-1 / 1.201235 \mathrm{e}+0$ & $9.085193 \mathrm{e}-2 / 7.680528 \mathrm{e}+0$ & $8.943304 \mathrm{e}-3$ \\
\hline & 3 & $6.063560 \mathrm{e}+0$ & $3.993432 \mathrm{e}-1 / 1.201235 \mathrm{e}+0$ & $9.085193 \mathrm{e}-2 / 7.680528 \mathrm{e}+0$ & $8.943304 \mathrm{e}-3$ \\
\hline & 4 & $6.061016 \mathrm{e}+0$ & $3.993615 \mathrm{e}-1 / 9.831564 \mathrm{e}-1$ & $8.806203 \mathrm{e}-2 / 6.280863 \mathrm{e}+0$ & $6.915064 \mathrm{e}-4$ \\
\hline \multirow{4}{*}{24} & 1 & $9.372070 \mathrm{e}-1$ & $1.689666 \mathrm{e}-3 / 1.867835 \mathrm{e}-4$ & $1.146255 \mathrm{e}-2 / 2.722810 \mathrm{e}-3$ & $3.193948 \mathrm{e}-3$ \\
\hline & 2 & $9.372070 \mathrm{e}-1$ & $1.689666 \mathrm{e}-3 / 1.867835 \mathrm{e}-4$ & $1.146255 \mathrm{e}-2 / 2.722810 \mathrm{e}-3$ & $3.193948 \mathrm{e}-3$ \\
\hline & 3 & $9.372070 \mathrm{e}-1$ & $1.689666 \mathrm{e}-3 / 1.867835 \mathrm{e}-4$ & $1.146255 \mathrm{e}-2 / 2.722810 \mathrm{e}-3$ & $3.193948 \mathrm{e}-3$ \\
\hline & 4 & $9.332077 \mathrm{e}-1$ & $1.305979 \mathrm{e}-3 / 2.825016 \mathrm{e}-4$ & $9.410819 \mathrm{e}-3 / 2.578198 \mathrm{e}-3$ & $3.231230 \mathrm{e}-3$ \\
\hline
\end{tabular}

Table 5: Validation results (8-MMBP) 


\begin{tabular}{|c||c|c|c|}
\hline \multirow{2}{*}{\multicolumn{1}{|c||}{ Rule }} & \multicolumn{3}{c|}{$\epsilon_{D}(n)$} \\
\cline { 2 - 4 } & Best & Worst & Average \\
\hline 1 & $5.792342 \mathrm{e}-5$ & $2.314937 \mathrm{e}-2$ & $4.566302 \mathrm{e}-3$ \\
\hline 2 & $5.792342 \mathrm{e}-5$ & $3.450790 \mathrm{e}-2$ & $4.373037 \mathrm{e}-3$ \\
\hline 3 & $4.621978 \mathrm{e}-5$ & $4.960103 \mathrm{e}-2$ & $5.541830 \mathrm{e}-3$ \\
\hline 4 & $4.621978 \mathrm{e}-5$ & $5.051155 \mathrm{e}-2$ & $4.963373 \mathrm{e}-3$ \\
\hline
\end{tabular}

Table 6: Summary of test results for rule $i, i=1,2,3,4$

\begin{tabular}{|c||c|c|c|c|c|}
\hline \multicolumn{1}{|c||}{ Example } & \multicolumn{5}{c|}{ Arrival Process } \\
\cline { 2 - 6 } & $m$ & $\rho_{\boldsymbol{A}}$ & $C_{A}^{2}$ & $\psi_{A}(1)$ & $\phi_{\boldsymbol{A}}(1)$ \\
\hline 1 & 4 & $4.857955 \mathrm{e}-01$ & $2.979940 \mathrm{e}+01$ & $4.855493 \mathrm{e}-01$ & $6.886441 \mathrm{e}-01$ \\
\hline 2 & 8 & $5.213512 \mathrm{e}-01$ & $2.294675 \mathrm{e}+01$ & $4.862596 \mathrm{e}-01$ & $5.265493 \mathrm{e}-01$ \\
\hline
\end{tabular}

Table 7: The arrival processes 

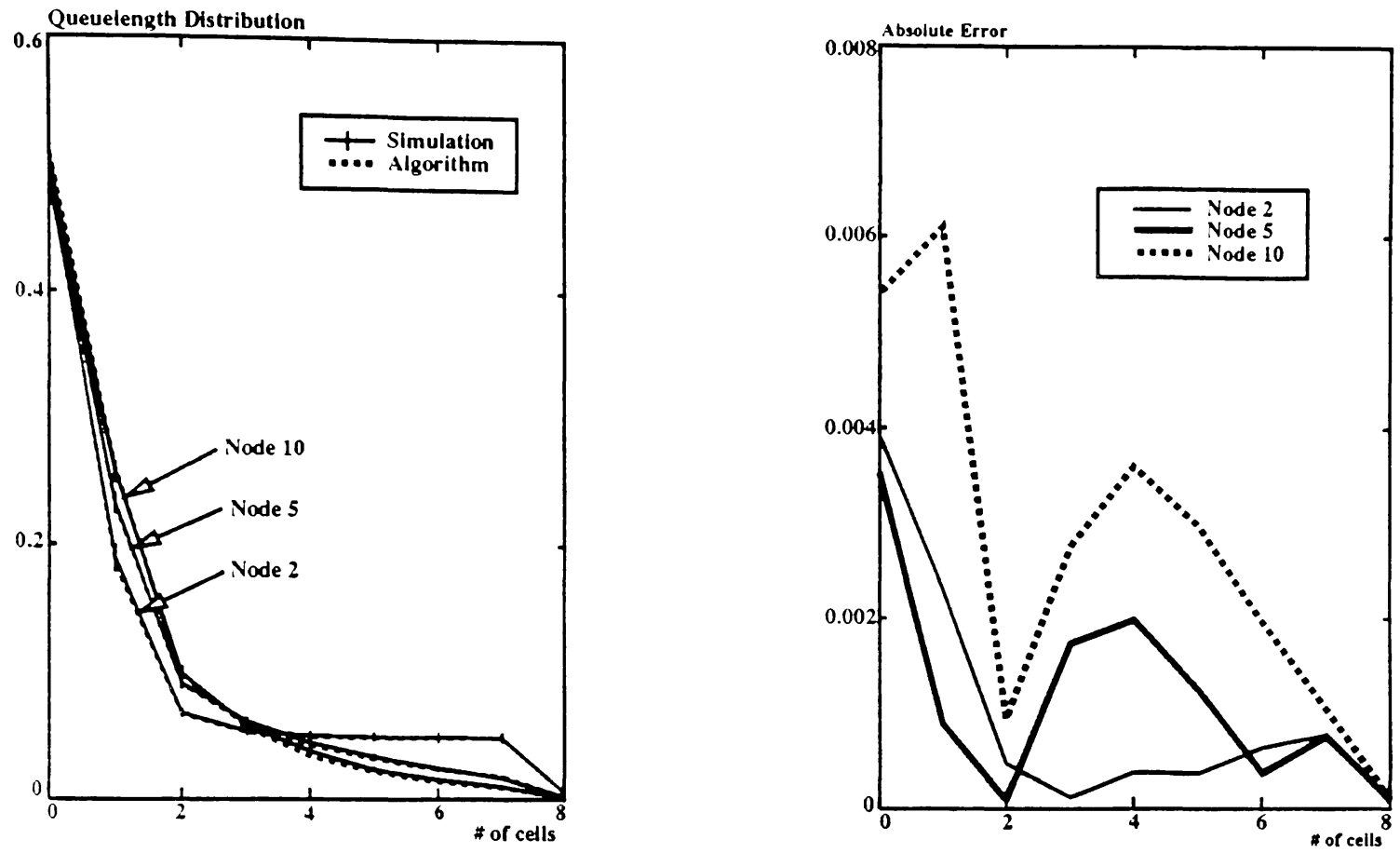

Figure 2: QLD and relative error (example 1)
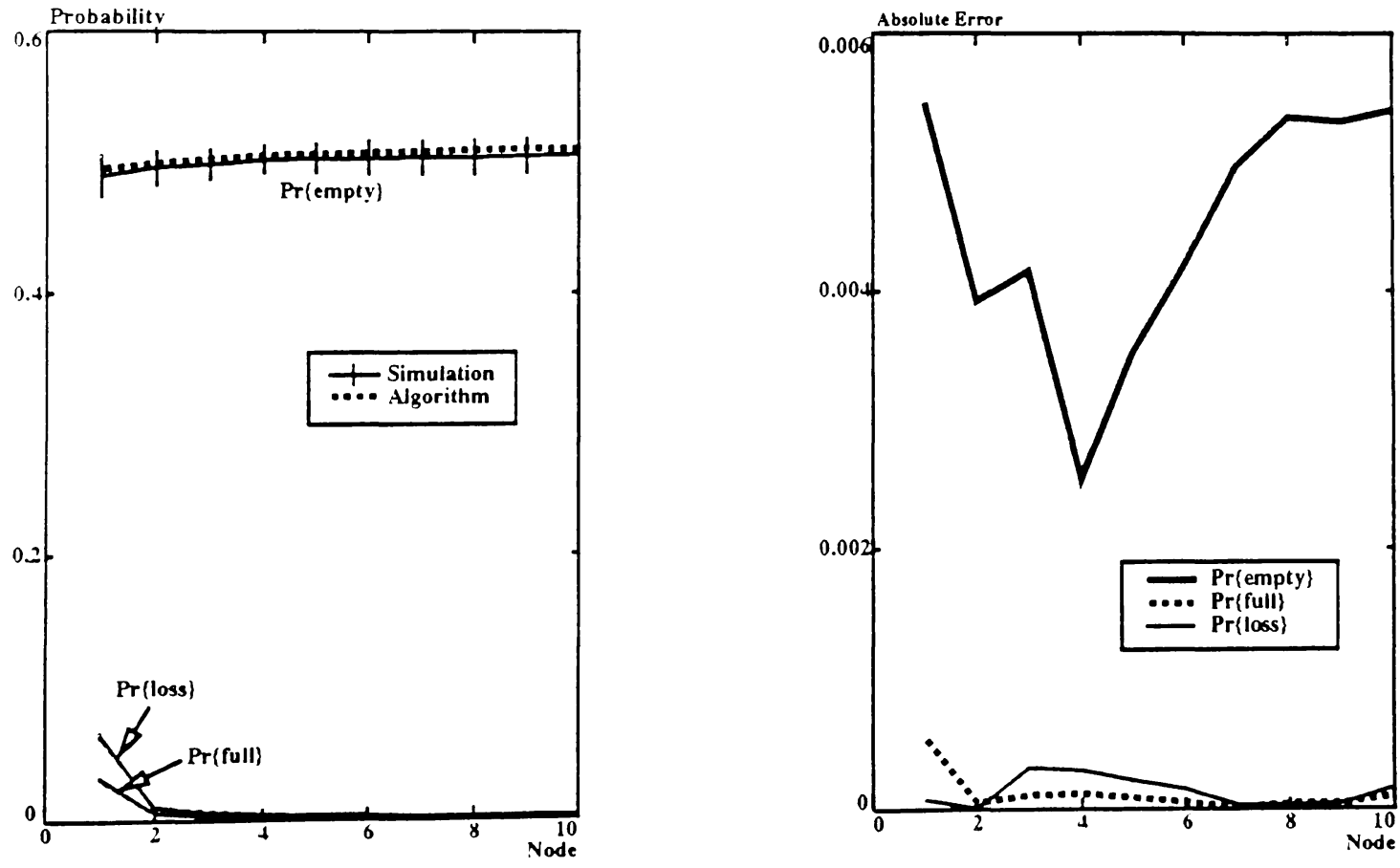

Figure 3: $P(0), P(K)$, and $P_{\text {loss }}$ and relative errors (example 1) 

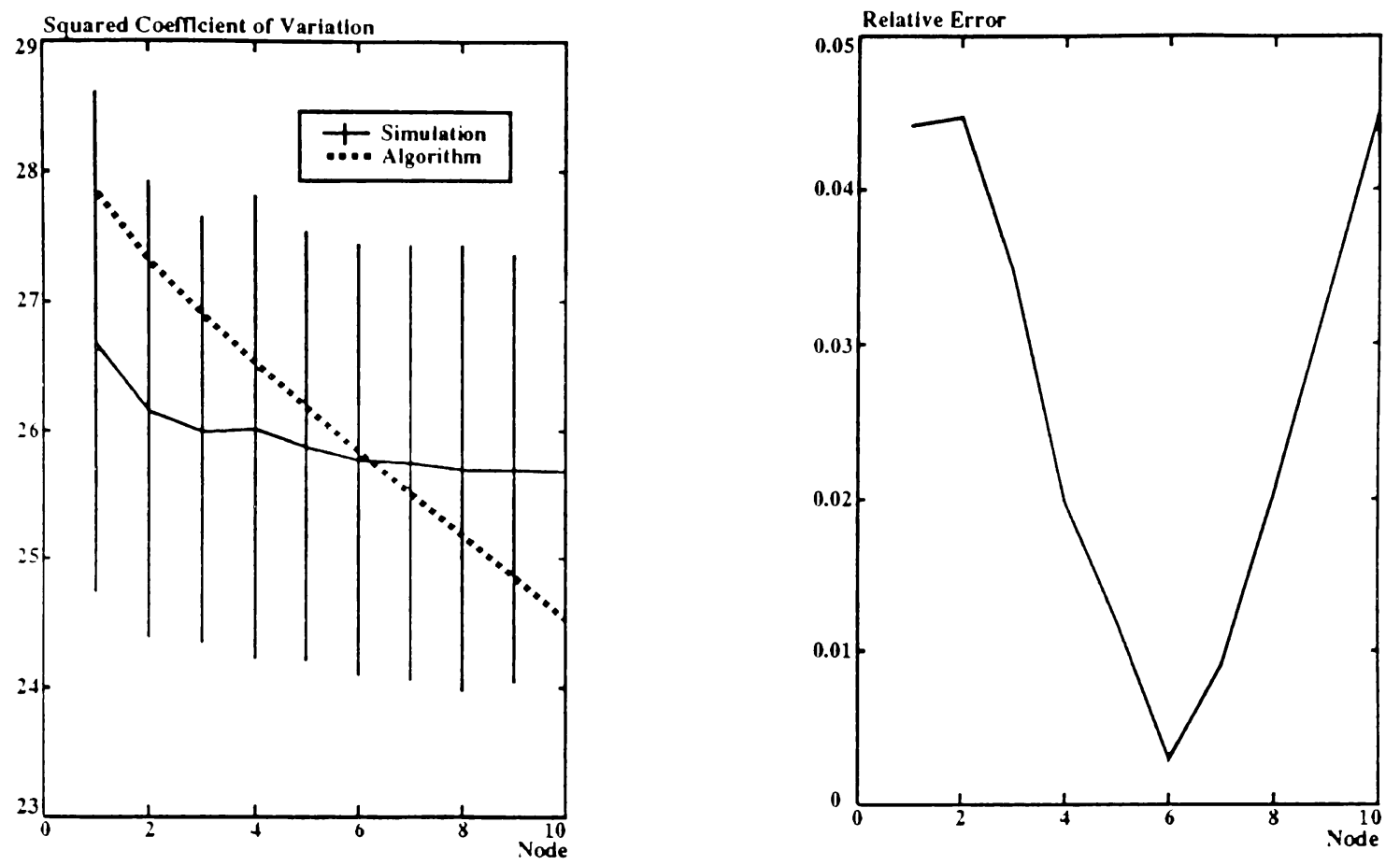

Figure 4: $C_{d}^{2}$ and relative error (example 1)
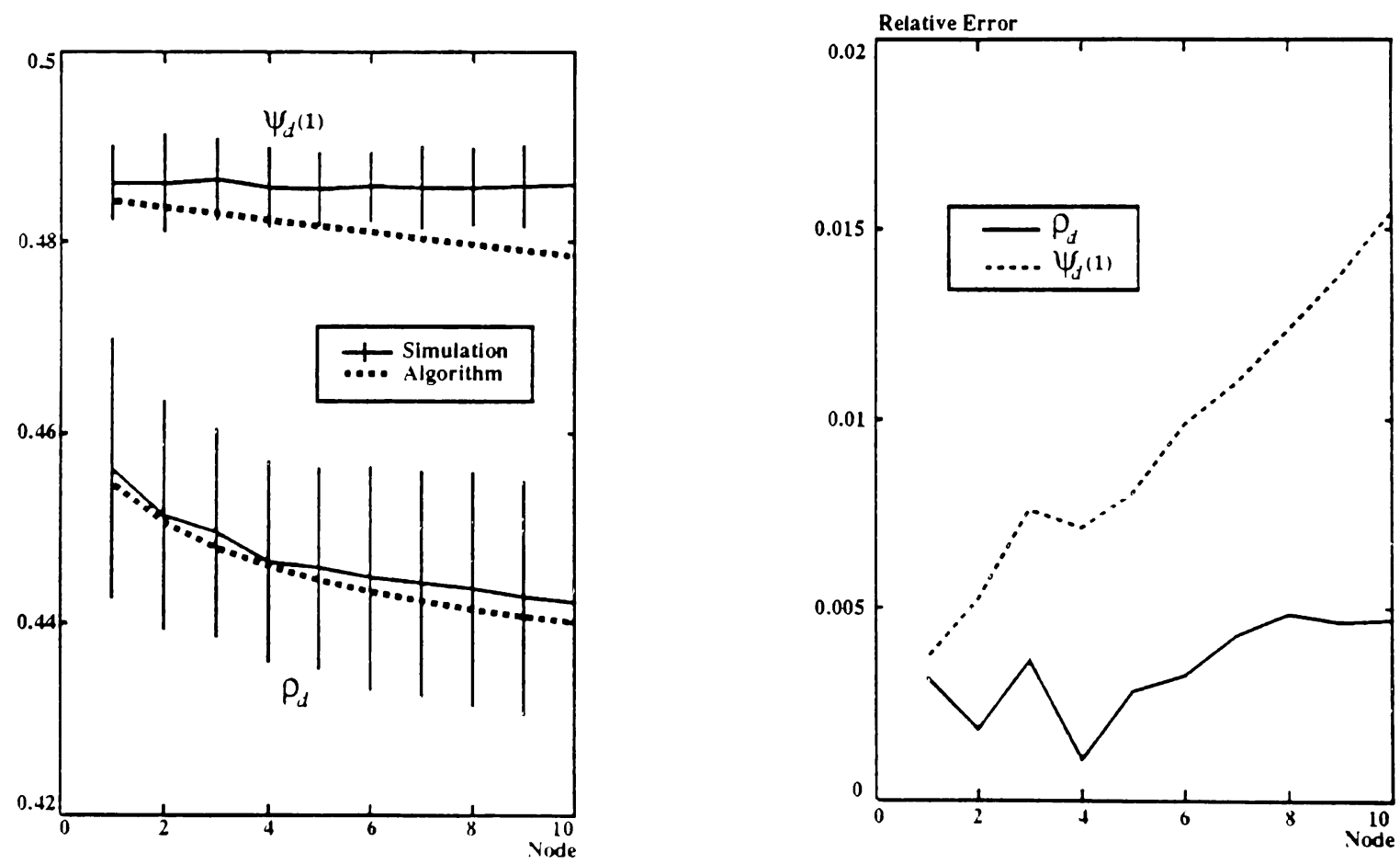

Figure 5: $\rho_{d}$ and $\psi_{d}(1)$ and relative errors (example 1) 

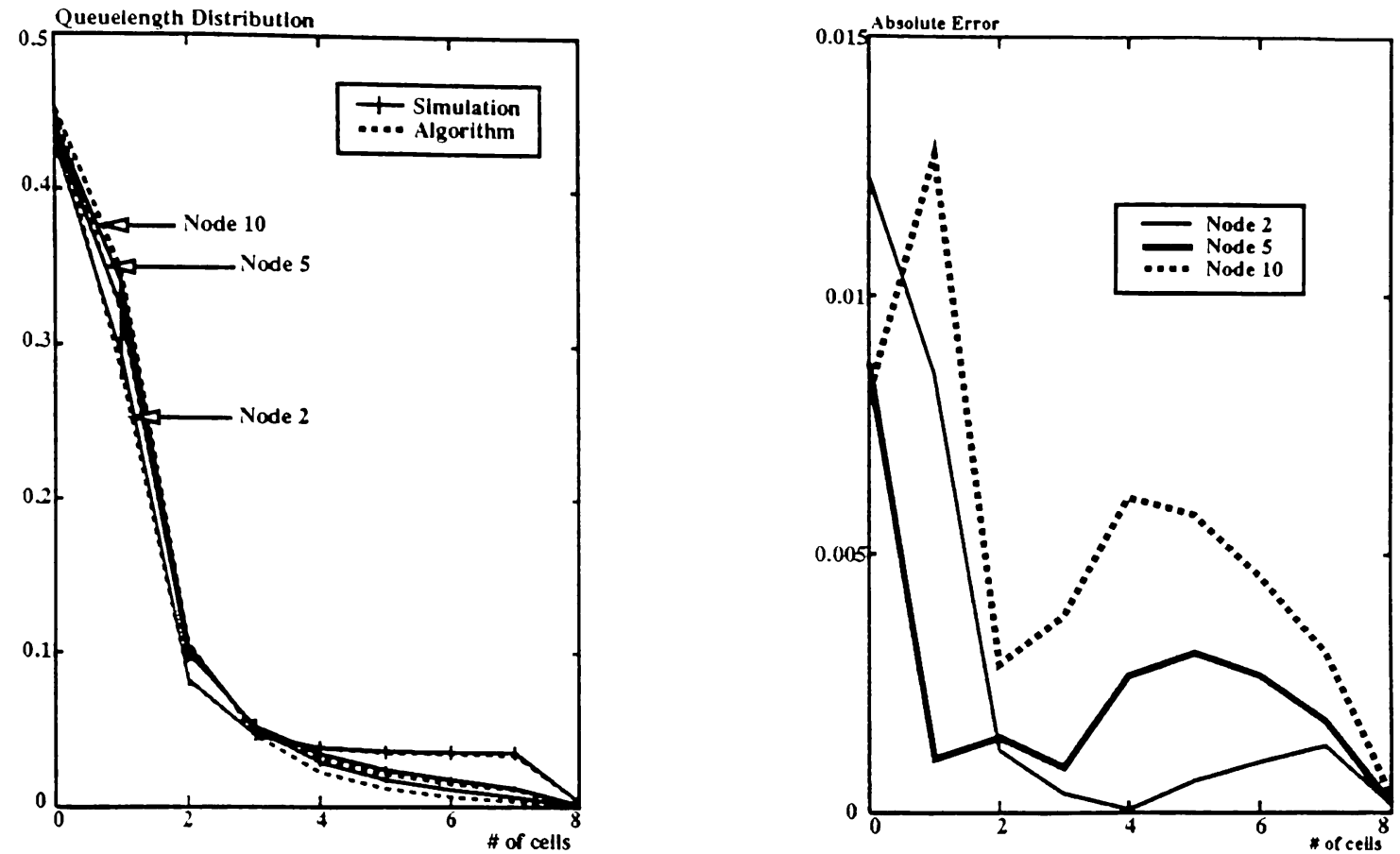

Figure 6: QLD and relative error (example 2)
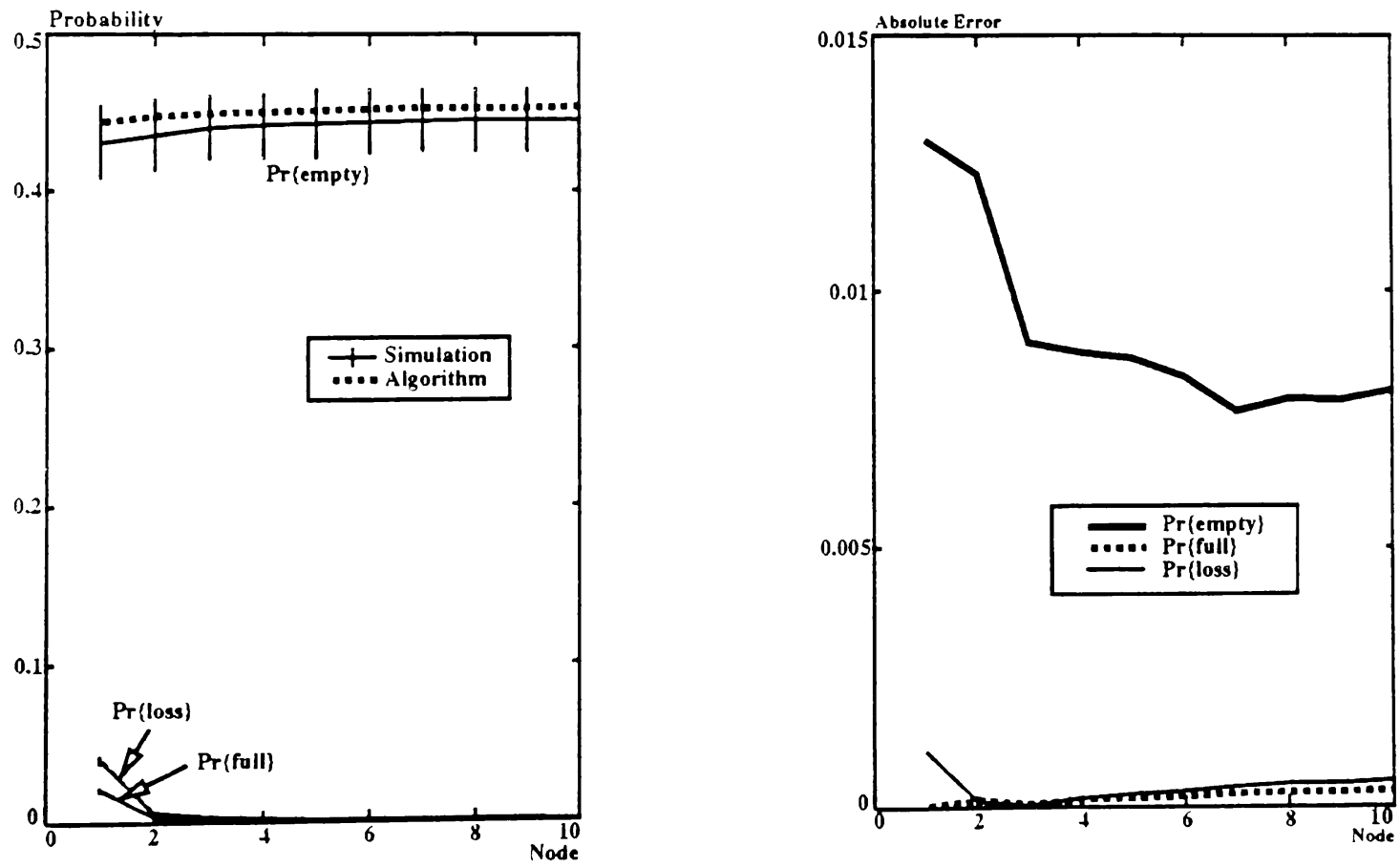

Figure 7: $P(0), P(K)$, and $P_{\text {loss }}$ and relative errors (example 2) 

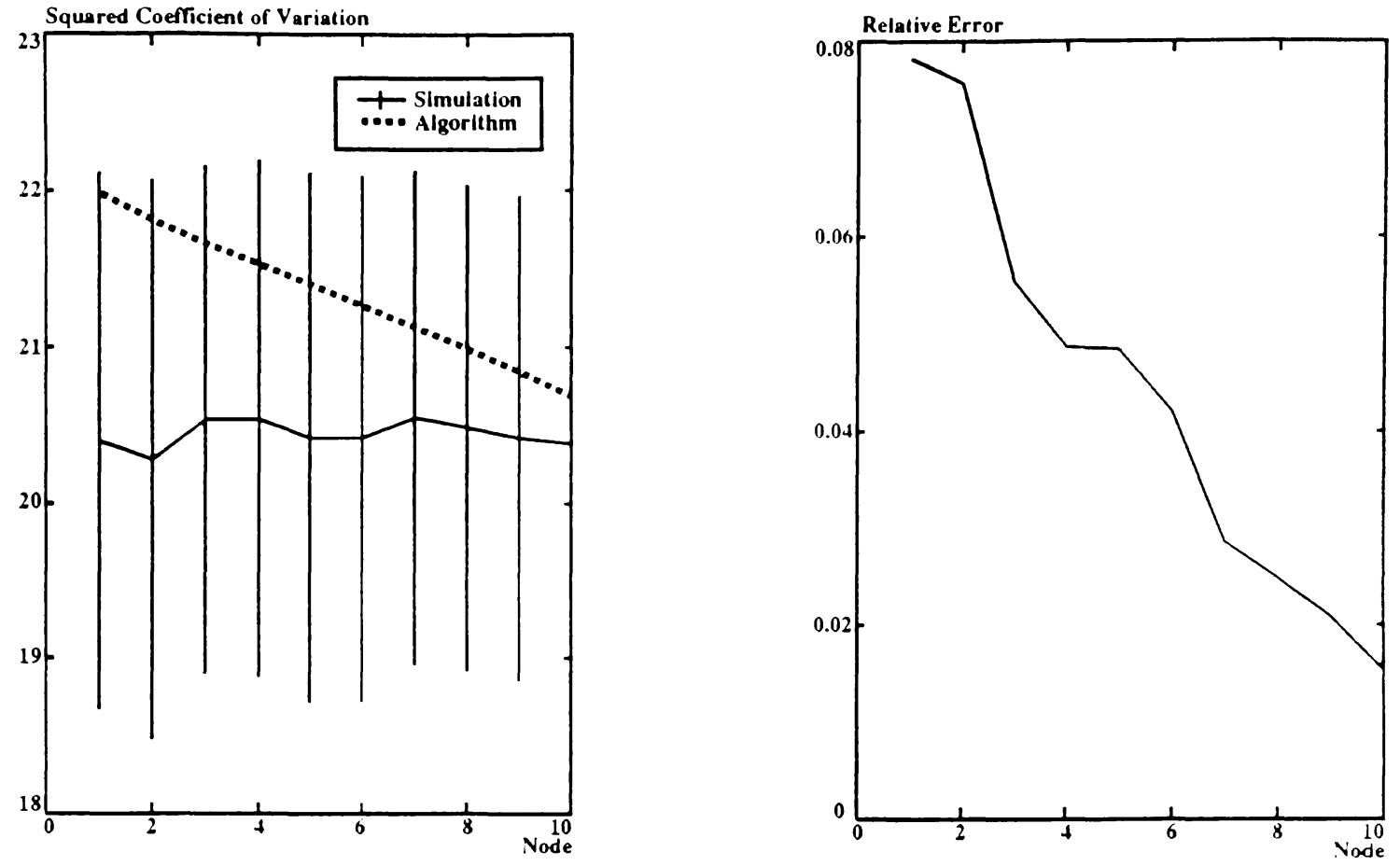

Figure 8: $C_{d}^{2}$ and relative error (example 2)
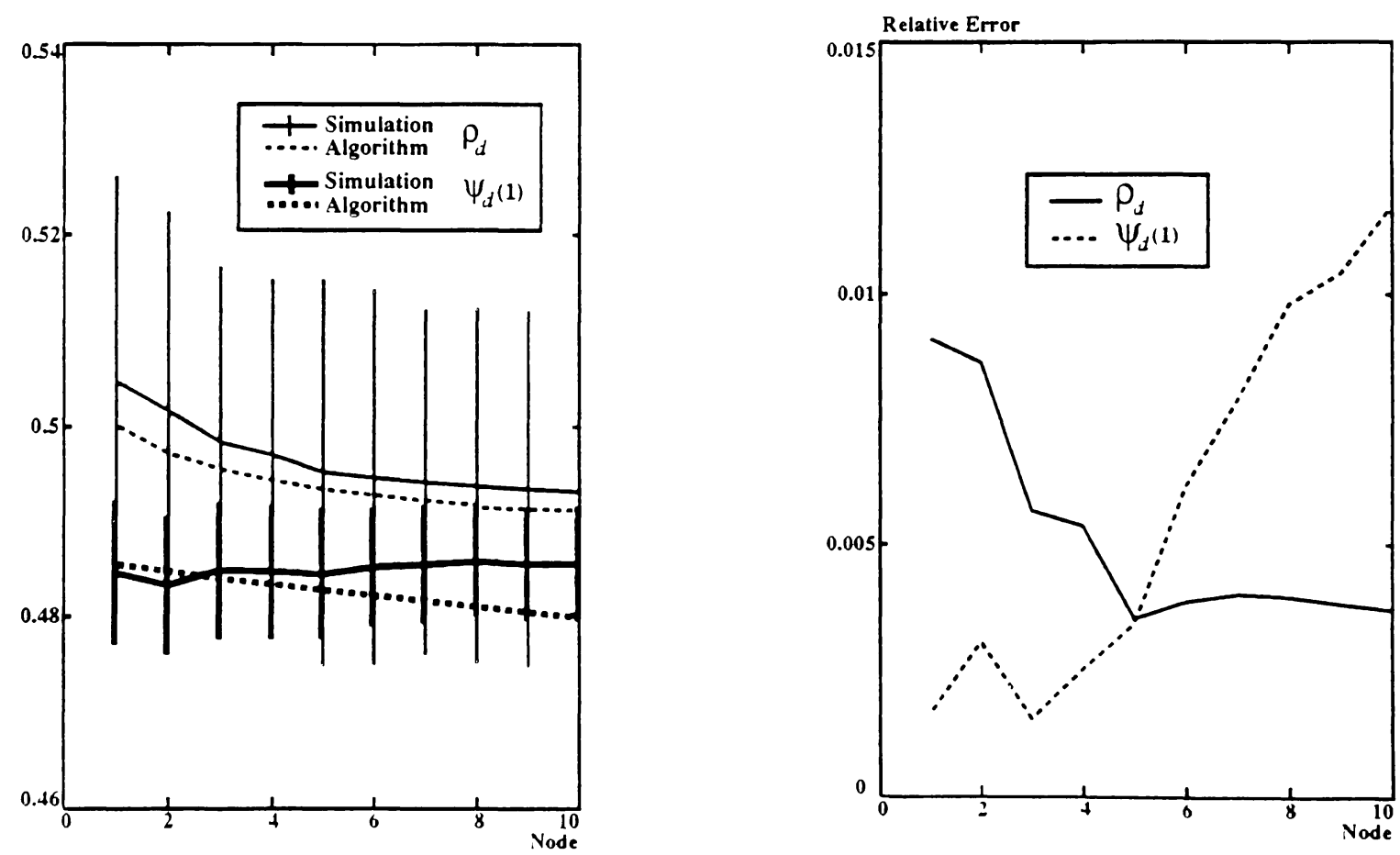

Figure 9: $\rho_{d}$ and $\psi_{d}(1)$ and relative errors (example 2) 


\section{References}

[1] G. Pujolle and H. G. Perros, "Queueing systems for modelling ATM networks," in Proc. of the Int'l. Conf. on the Performance of Distributed Systems and Integrated Comm. Networks, pp. 10-12, Kyoto, Japan, Sept. 1991.

[2] H. Heffes and D. M. Lucantoni, "A Markov modulated characterization of packetized voice and data traffic and related statistical multiplexer performance," IEEE J. Select. Areas Commun., vol. 4, pp. 856-868, 1986.

[3] W. Fischer and K. Meier-Hellstern. The MMPP cookbook. Technical report, Bell Lab., 1990.

[4] D. Park and H. G. Perros, "Approximate analysis of discrete-time tandem queueing networks with customer loss," in IEEE, GLOBECOM'92, pp. 1503-1507, Olando, FL, 1992.

[5] D. Park, H. G. Perros, and H. Yamashita. Approximate analysis of discrete-time tandem queueing networks with bursty and correlated input traffic and customer loss. Technical report, Computer Science, North Carolina State University, Raleigh, NC, 1992.

[6] I. Starvrakakis, "Efficient modeling of merging and splitting processes in large networking structure," IEEE J. Select. Areas Commun., no. 8, Oct. 1991.

[7] K. Meier-Hellstern, "A fitting algorithm for Markov-modulated Poisson process having two arrival rates," E.J.O.R., vol. 29, pp. 370-377, 1987.

[8] P. Tran-Gia, "Discrete time analysis for the interdeparture distribution of GI/G/1 queue," in Teletraffic Analysis and Computer Performance Evaluation, pp. 341-357. O. J. Boxma, J. W. Cohen, and H.C. Tijms, Eds. North Holland:Elsevier Science, 1986. 
[9] Y. Ohba, M. Murata, and H. Miyahara, "Analysis of interdeparture process for bursty traffic in ATM networks," IEEE J. Select. Areas Commun., no. 3, pp. 468-476, Apr. 1991.

[10] O. Hashida, Y. Takahashi, and S. Shimogawa, "Switched Batch Bernoulli Pro$\operatorname{cess}(\mathrm{SBBP})$ and the discrete-time SBBP/G/1 queue with application to statistical multiplexer performance," IEEE J. Select. Areas Commun., no. 3, Apr. 1991.

[11] T. D. Morris and H. G. Perros, "Performance analysis of a multi-buffered Banyan ATM switch under bursty traffic," in INFOCOM 'g2, pp. 436-445, Florence, Italy, May 1992. 